Canadian

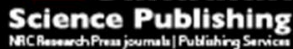

Canadian Geotechnical Journal Revue canadienne de géotechnique

\title{
A New Simplified Method and Its Verification for Calculation of Consolidation Settlement of a Clayey Soil with Creep
}

\begin{tabular}{|r|l|}
\hline Journal: & Canadian Geotechnical Journal \\
\hline Manuscript ID & cgj-2015-0290.R3 \\
\hline Danuscript Type: & Article \\
\hline Complete List of Authors: & $\begin{array}{l}\text { Yin, Jian-Hua; The Hong Kong Polytechnic University, Department of Civil } \\
\text { and Environmental Engineering } \\
\text { Feng, Wei-Qiang; The Hong Kong Polytechnic University, Department of } \\
\text { Civil and Environmental Engineering }\end{array}$ \\
\hline Keyword: & consolidation, settlement, time-dependent, clay, visco-plastic \\
\hline \multicolumn{2}{|r}{} \\
\hline
\end{tabular}




\title{
A New Simplified Method and Its Verification for Calculation of
}

\section{Consolidation Settlement of a Clayey Soil with Creep}

\author{
by \\ Jian-Hua YIN \\ Department of Civil and Environmental Engineering \\ The Hong Kong Polytechnic University \\ Hung Hom, Kowloon, Hong Kong, China
}

Tel: (852) 2766-6065, Fax: (852) 2334-6389, Email: cejhyin@polyu.edu.hk

Wei-Qiang Feng

Department of Civil and Environmental Engineering,

The Hong Kong Polytechnic University

Hung Hom, Kowloon, Hong Kong.

Email: 11901182r@connect.polyu.hk

Revised manuscript submitted to Canadian Geotechnical Journal for possible publication as an Article

21 June 2016

-1 - 


\section{Abstract:}

The calculation of the consolidation settlement of clayey soils with creep behaviour has been a challenging issue with a long history. After a brief review the assumptions made in the two methods based on Hypothesis A and Hypothesis B, the authors present a new simplified Hypothesis B method for calculation of consolidation settlement of a clayey soil with creep. Equations of this method are derived based on the "equivalent time" concept for different stress-strain states. This simplified Hypothesis B method is then used to calculate the consolidation settlement of a number of typical consolidation problems. The approximation and verification of this simplified method are examined by comparing the calculated settlements with settlements computed using two fully coupled finite element consolidation analysis programs using elastic visco-plastic constitutive models (Hypothesis B) and the Hypothesis A method. It is found that the curves calculated using the new Hypothesis B simplified method with a factor $\alpha=0.8$ are close to curves from two Finite Element (FE) model simulations with relative errors in the range of $0.37 \% \sim 8.42 \%$ only for three layers of Hong Kong Marine Clay (HKMC). In overall, the settlements calculated using Hypothesis A method are smaller than those from the two FE simulations with relative error in the range of $6.52 \% \sim 46.17 \%$ for the three layers of HKMC. In addition, this new simplified Hypothesis B method is used to calculate the average strain of consolidation tests done by Berre and Iversen (1972). The calculated results are compared with the test data, and values from a fully coupled finite difference consolidation analysis using Yin and Graham's elastic visco-plastic constitutive model (Hypothesis B), and Hypothesis A method. It is found that, again, the results from the new simplified Hypothesis B method are very close the measured data. In conclusion, the new simplified Hypothesis B method is a suitable simple method, by spread-sheet calculation of the consolidation settlement of a single layer of a clayey soil with creep.

Keywords: clay, settlement, consolidation, time-dependent, creep, visco-plastic 


\section{Introduction}

It is well known that the stress-strain behaviour of clayey soils is time-dependent due to the viscous nature of the skeleton of the soils (Bjerrum 1967; Graham et.al. 1983; Leroueil et.al. 1985; Olson 1998). The physical phenomena such as creep, relaxation, strain rate effects, "apparent reconsolidation pressure", etc. are all part of the time-dependent stress-strain behaviour. Under loading, the clayey soils in a saturated condition are subjected to consolidation process, in which the excess porewater pressure dissipates with time, resulting in compression of the soils or settlement. For the design of structures, such as reclamation or foundation on the clayey soils, we need to calculate the consolidation settlement of the soils with certain accuracy.

Terzaghi (1943) first presented a theory and equations for analysis of the consolidation of soil in one-dimensional (1-D) straining (oedometer condition). His 1-D consolidation theory was based on eight assumptions (Terzaghi 1943; Craig 2004). The most questionable assumption is that "there is a unique relationship, independent of time, between void ratio and effective stress" (Craig 2004). In fact, the relationship between void ratio and effective stress is time-dependent and strain-rate dependent. Therefore, in reality, Terzaghi's 1-D consolidation theory cannot be applied to consolidation settlement calculation of clayey soils with creep. Many researchers have taken efforts to propose improved methods for calculation of consolidation settlement of clayey soils by considering creep. These improved methods can be divided in two types: one is based on Hypothesis A (Ladd et. al. 1977; Mesri and Godlewski 1977) and the other one is based on Hypothesis B (Gibson and Lo 1961; Barden 1965, 1969; Bjerrum 1967; Garlanger 1972; Leroueil et.al. 1985; Hinchberger and Rowe 2005; Kelln, et al. 2008). The assumptions used in the two methods are examined more closely in the following paragraphs.

It shall be pointed out that the calculation of consolidation settlement in this paper is -3 - 
confined to the case of one-dimensional straining (1-D straining) condition and one single soil layer with constant soil properties. The assumptions used in the method based on Hypothesis A for the calculation of consolidation settlement are:

(a) There exists a so-called "End-of-Primary" (EOP) point between "primary consolidation" period and "secondary compression" without excess porewater pressure $\left(u_{e}=0\right)$ with the corresponding time $t_{E O P}$ (see Figure 1).

(b) There is no creep compression during the "primary consolidation" period; but the creep compression occurs only in the "secondary compression" starting at $t_{E O P}$ (see Figure 1).

(c) The creep compression occurs in the "secondary compression" period can be described by the "secondary consolidation coefficient" $C_{\alpha e}$ which is $C_{\alpha e}=\frac{-\Delta e}{\Delta \log t}$, where $e$ is void ratio and $t$ is the duration time of the present loading (see Figure 1).

Based on the above assumptions, a mathematical equation of the method based on Hypothesis A for the calculation of the total consolidation settlement $S_{\text {totalA }}$ in the field is:

$$
\begin{aligned}
& S_{\text {totalA }}=S_{\text {"primary" }}+S_{\text {secondary" }} \\
& = \begin{cases}U_{v} S_{f} & \text { for } t<t_{E O P, \text { field }} \\
U_{v} S_{f}+\frac{C_{\alpha e}}{1+e_{o}} \log \left(\frac{t}{t_{E O P, \text { field }}}\right) H & \text { for } t>t_{E O P, \text { field }}\end{cases}
\end{aligned}
$$

where $S_{\text {"primary" }}$ is the "primary consolidation" settlement at time $t$ and is equal to $U_{v} S_{f}$ in which $U_{v}$ is the average degree of consolidation and $S_{f}$ is the final "primary consolidation" settlement. In Eq.(1), $e_{o}$ is the initial void ratio. The "secondary" compression settlement is $S_{\text {"secondary" }}=\frac{C_{\alpha e}}{1+e_{o}} \log \left(\frac{t}{t_{E O P, \text { field }}}\right) H$ and is calculated since $t>t_{E O P, \text { field }}$ which is the time at "EOP" in the field condition. The $t_{E O P, \text { field }}$ is dependent on the thickness of the soil layer and hydraulic permeability of the soil. The two main problems in Eq.(1) are as follows:

(a) The separation of the "primary consolidation" period and "secondary consolidation" period is subjective and not accurate. According to the Tergazhi's 1-D consolidation - 4 - 
theory, the time corresponding to excess porewater pressure $u_{e}=0$, that is, $U_{v}=100 \%$, is infinite, that is, $t_{E O P \text {,field }}$ shall be infinite. To get around this problem, it is often assumed that the time corresponding to $U_{v} \geq 98 \%$ is the time $t_{E O P, f i e l d}$ at "EOP".

(b) There is no creep when time $t<t_{E O P, \text { field }}$ as shown in Eq.(1), that is, no creep in the "primary consolidation"; however creep occurs right after $t_{E O P, f i e l d}$ as "secondary compression"

In fact, under the action of the effective stress, the skeleton of a clayey soil exhibits viscous deformation, or ongoing settlement in 1-D straining case. Even in the "primary consolidation" period, there are effective stresses, which may vary significantly with time. The rate of creep compression depends on the state of consolidation such as normal consolidation or over-consolidation. Therefore, due to the exclusion of creep compression in the "primary consolidation" period, the method based on Hypothesis A normally underestimates the total consolidation settlement.

In a different approach, the method based on Hypothesis B does not need these assumptions in Hypothesis A. The method based on Hypothesis B is a coupled consolidation analysis using a proper constitutive relationship for the time-dependent stress-strain behaviour of clayey soils. The time-dependent compression of the clay skeleton, for example, creep in the "primary consolidation", is naturally included in the coupled consolidation analysis. The equations of the method based Hypothesis B can be expressed as follows:

From the mass continuity condition, we can derive:

$$
\frac{k}{\gamma_{w}} \frac{\partial^{2} u_{e}}{\partial z^{2}}=-\frac{\partial \varepsilon_{z}}{\partial t}
$$

where $k$ is the vertical hydraulic conductivity (assumed to be constant here for simplicity); $\gamma_{w}$ is the unit weight of water; $u_{e}$ is the excess porewater pressure; and $\varepsilon_{z}$ is the vertical strain (compression strain is positive here). There are two unknowns in Eq.(2), that is, 
$u_{e}, \varepsilon_{z}$. A constitutive model equation is needed.

Yin and Graham $(1989,1994)$ developed, validated, and applied a 1D Elastic Visco-Plastic (1D EVP) constitutive model for the time-dependent stress-strain behaviour of clayey soils. The 1D EVP constitutive model equation is:

$$
\dot{\varepsilon}_{z}=\frac{\kappa}{V} \frac{\dot{\sigma}_{z}^{\prime}}{\sigma_{z}^{\prime}}+\frac{\psi}{V t} \exp \left[-\left(\varepsilon_{z}-\varepsilon_{z o}^{e p}\right) \frac{V}{\psi}\right]\left(\frac{\sigma_{z}^{\prime}}{\sigma_{z o}^{\prime}}\right)^{\lambda / \psi}
$$

where $\dot{\varepsilon}_{z}$ and $\varepsilon_{z}$ are the vertical strain rate and strain; $\dot{\sigma}_{z}^{\prime}$ and $\sigma_{z}^{\prime}$ are the vertical effective stress rate and effective stress; $V$ is equal to $\left(1+e_{o}\right)$, called specific volume; $\kappa / V$ together is considered to be one parameter related the elastic compression of the soil; The three parameters $\lambda / V, \varepsilon_{z o}^{e p}, \sigma_{z o}^{\prime}$ define a "reference time line" (Yin and Graham 1989, 1994) and are related to the normal compression line of the soil; and the two parameters $\psi / V$ and $t_{o}$ are related to the creep compression of the soil. The 1D EVP model in Eq.(3) is an extension of the Maxwell's linear elastic visco-plastic model in which a linear elastic spring is connected to a linear viscous dash pot (Yin 2015).

For a soil layer in 1-D straining, the total stress $\sigma_{z}$ and original or static porewater pressure $u_{s}$ in the soil layer are normally known. Therefore, according to the effective stress principle and noting the total porewater pressure $u=u_{s}+u_{e}$ we have

$$
\begin{gathered}
\sigma_{z}^{\prime}=\sigma_{z}-u=\sigma_{z}-u_{s}-u_{e} \text {. Submitting } \sigma_{z}^{\prime}=\sigma_{z}-u=\sigma_{z}-u_{s}-u_{e} \text { into Eq.(3), we have: } \\
\frac{\partial \varepsilon_{z}}{\partial t}=\frac{\kappa}{V} \frac{1}{\left(\sigma_{z}-u_{s}-u_{e}\right)} \frac{\partial\left(\sigma_{z}-u_{s}-u_{e}\right)}{\partial t}+\frac{\psi}{V t_{o}} \exp \left[-\left(\varepsilon_{z}-\varepsilon_{z o}^{e p}\right) \frac{V}{\psi}\right]\left(\frac{\left.\sigma_{z}-u_{s}-u_{e}\right)}{\sigma_{z o}^{\prime}}\right)^{\lambda / \psi}
\end{gathered}
$$

By solving Eq.(2) together with Eq.(4), we can obtain the excess porewater pressure $u_{e}$, from which, we can obtain the effective stress $\sigma_{z}^{\prime}$, the vertical strain $\varepsilon_{z}$ and the total settlement $S_{\text {totalB }}=\int_{o}^{H} \varepsilon_{z} d z$, where $H$ is the total thickness of the soil layer.

Yin and Graham (1996) used a finite difference method to solve Eqs.(2) and (4) from -6 https://mc06.manuscriptcentral.com/cgj-pubs 
Hypothesis B and obtained curves of the settlement, strains, and excess porewater pressure with time. They used this approach to calculate the settlement and excess porewater pressure of a clay in laboratory physical model tests done by Berre and Iversen (1972). The calculated data were compared with the measured data by Berre and Iversen (1972) in good agreement. They also found that the method based on Hypothesis A underestimated the total settlement.

Nash and Ryde $(2000,2001)$ used the method based Hypothesis B with the constitutive equation in Eq.(3) to analyze the 1-D consolidation settlement of an embankment on soft ground with vertical drains. They used a finite difference method (Yin and Graham 1996) to solve the coupled consolidation equations. Their computed settlement values were in good agreement with the observed values.

One limitation of the above rigorous Hypothesis B method is that a numerical method is needed to solve a set of non-linear partial different equations and a computer program for this method is needed. Such computer program is still not readily available to engineers or difficult for them to use. How to develop a simple method, which is a good approximation of the solutions from the above rigorous method and, at the same time, is easy to use by engineers, has been a very challenge task in past decades. The main objective of this paper is to propose a new simplified method based on Hypothesis B for easy spread-sheet calculation of consolidation settlements of clayey soils with creep and the verification of this simplified method.

\section{Main Equation of a New Simplified Method Based on Hypothesis B for Settlement Calculation of a Soil Layer with Creep}

The key point in the new simplified method based on Hypothesis B (called a new simplified Hypothesis B method) is that creep occurs in the whole consolidation period, both within and after the "primary consolidation", as shown in Figure 1. The main equation of the new simplified Hypothesis B method for the calculation of the total consolidation settlement

- 7 - 
$S_{\text {totalB }}$ can be expressed as:

$$
\begin{aligned}
S_{\text {totalB }} & =S_{\text {"primary" }}+S_{\text {creep }} \\
& =U_{v} S_{f}+\left[\alpha S_{\text {creep }, f}+(1-\alpha) S_{\text {secondary" }}\right] \quad \text { for all } t \geq 1 \text { day } \quad\left(t \geq t_{E O P, \text { field }} \text { for } S_{\text {"secondary" }}\right)
\end{aligned}
$$

where $S_{\text {creep,f }}$ is the creep settlement under the final effective vertical stress without excess pore water pressure coupling; $S_{\text {"secondary" }}$ is the same as that in Eq.(1) and $t_{E O P, \text { field }}$ is the time at $U_{v}=98 \%$.

In Eq.(5), a parameter $\alpha$ is introduced and shall be in the range from 0 to 1 , that is, $0 \leq \alpha \leq 1$. If $\alpha=1$, Eq.(5) becomes the old Yin's simplified Hypothesis B method (Yin 2011). If $\alpha=0$, Eq.(5) becomes Hypothesis A method in Eq.(1). The most suitable value $\alpha$ will be determined by comparing the calculated settlement using Eq.(5) with settlements from coupled consolidation analysis later in this paper. Comparing Eq.(5) to Eq.(1), it is seen that the creep settlement $S_{\text {creep }}$ is included for the loading time $t \geq 0$, that is, creep compression occurs from the beginning.

It is noted that $S_{\text {creep }}=\left[\alpha S_{\text {creep }, f}+(1-\alpha) S_{\text {"sec ondary" }}\right]$ in Eq.(5). It is noted that Yin (2011) proposed a simplified method by using $S_{\text {creep }}=S_{\text {creep }, f}$, that is, the case $\alpha=1$ in Eq.(5). It is found that the total consolidation settlement using $S_{\text {creep }}=S_{\text {creep }, f}$ is overestimated. For example, as shown in Figure 2, if the initial effective stress-strain state is at Point 1 and the final effective stress-strain state is at Point $4, S_{\text {creep }, f}$ is calculated to be the creep under the final effective stress $\sigma_{z 4}^{\prime}$. This path from Point 1 to Point 3 to Point 4 is assumed to be an instant loading path without excess porewater pressure coupling. This path may be ok for the soil at the drainage boundary. However, the effective stress-strain paths inside the clay away from the drainage boundary will be delayed as shown in Figure 2. This is why the use of $S_{\text {creep }}=S_{\text {creep }, f}$ with $\alpha=1$ in Eq.(5) will over-estimate the creep settlement. It is also noted 
that when $\alpha=0, S_{\text {creep }}=S_{\text {"secondary" }}$ which is calculated for $t \geq t_{E O P, \text { field }}$. This approach is based on Hypothesis A which underestimates the settlement as explained before since ignoring creep in the primary consolidation period. The new simplified Hypothesis B method in Eq.(5) with a suitable value of $\alpha$ takes a more accurate approach to calculating the creep settlement during and after primary consolidation. It is found later in this paper that if $\alpha=0.8$, the settlements calculated using this new simplified Hypothesis B method are closer to the settlements from the fully coupled consolidation modelling.

The $S_{f}$ in Eq.(5) is normally calculated using the "swelling" index $C_{e}$, that is, unloading/reloading (or the over-consolidation compression) slope and compression index $C_{c}$ using the compression data from oedometer tests. It shall be noted that the compression of a clayey soil is time-dependent. The selection of the compression data at different times will result in different compression curves. For example, referring to Figure 1 under a certain vertical stress, the compression can be selected as the value at the "End Of Primary" consolidation in lab $\left(t_{E O P, l a b}\right)\left(t_{E O P, l a b}\right.$ is normally a few minutes) or the time at 24 hours, $\left(t_{24}\right)$. If we plot the compressions and corresponding stresses for the two durations of $t_{E O P, l a b}$ and $t_{24}$, we have the two curves as shown in Figure 3. It is noted that the curve using data at $t_{E O P, l a b}$ is normally above the curve using data at $t_{24}$. The two slopes in the normal consolidation section given by the compression index $C_{c}$ at $t_{E O P, l a b}$ and $C_{c}$ at $t_{24}$ are about the same. In the over-consolidation range, the slope is given by $C_{e}$ which is considered to be the same for the two durations $\left(t_{E O P, l a b}\right.$ and $\left.t_{24}\right)$. It is also noted that the curve in unloading or reloading is normally a loop, but, is normally simplified as a straight line with the same slope of $C_{e}$ as in the over-consolidation range. The only difference of the two curves in Figure 3 is the points of the pre-consolidation stress and strain, that is, the point $\left(\sigma_{z p}^{\prime}, \varepsilon_{z p}\right)$ at $t_{E O P, l a b}$ shall be higher than $\left(\sigma_{z p}^{\prime}, \varepsilon_{z p}\right)$ at $t_{24 h o u r s}$. 
An oedometer test is normally done on the same specimen in oedometer in multi-stages. According to British Standard 1377 (1990), the duration for each load shall normally last for 24 hours. In this paper, we consider the indexes $C_{e}, C_{c}$ and $\left(\sigma_{z p}^{\prime}, \varepsilon_{z p}\right)$ are all determined from the standard oedometer test with duration of 24 hours (1 day) for each load. The idealized relationship between the vertical strain and the $\log$ (effective stress) is shown in Figure 2 with loading, unloading and reloading states. Based on Figure 2, the final settlements $S_{f}$ in Eq.(5) for two cases are calculated as follows:

(i) Point 1 to Point 2:

$$
S_{f}=\Delta \varepsilon_{z, 1-2} H=\frac{C_{e}}{1+e_{o}} \log \left(\frac{\sigma_{z 2}^{\prime}}{\sigma_{z 1}^{\prime}}\right) H
$$

The $\Delta \varepsilon_{z, 1-2}$ is the vertical strain increase due to stress increases from $\sigma_{z 1}^{\prime}$ to $\sigma_{z 2}^{\prime}$. Similar strain increase symbols are used in the following equations.

(ii) Point 1 to Point 4:

$$
S_{f}=\Delta \varepsilon_{z, 1-4} H=\left[\frac{C_{e}}{1+e_{o}} \log \left(\frac{\sigma_{z p}^{\prime}}{\sigma_{z l}^{\prime}}\right)+\frac{C_{c}}{1+e_{o}} \log \left(\frac{\sigma_{z 4}^{\prime}}{\sigma_{z p}^{\prime}}\right)\right] H
$$

The key part in Eq.(5) is how to calculate the creep settlement $S_{\text {creep }, f}$ at the final effective stress state. Other researchers such as Mesri and Godlewski (1977) and Mesri and Choi (1984) used the ratio of $C_{\alpha e} / C_{c}$ to obtain the "secondary" compression coefficient first and used it to calculate the secondary consolidation settlement. It is noted that the ratio of $C_{\alpha e} / C_{c}$ varies with over-consolidation ratio. Therefore, it is difficult to use this ratio to obtain the $C_{\alpha e}$ for various stress-strain state. They only started calculating creep strains after primary consolidation at EOP.

In this paper, the authors use only two parameters for creep compression in the normal consolidation condition, for the calculation of the creep settlement $S_{\text {creep,f }}$ under any loading condition, including over-consolidation, unloading and reloading conditions. The theoretical 
base of this method relies on the "equivalent time" concept (Bjerrum 1967 and Yin and Graham 1989, 1994).

Figure 4 illustrates curved "time lines" in the coordinates of vertical effective stress and void ratio from 1D straining oedometer tests (Bjerrum 1967). These parallel "time limes" also represent lines of constant plastic strain rate. Others, for example Kelln et al. (2008) have developed an elastic viscoplastic model that emphasises strain rates and otherwise is very compatible with the model by Yin and Graham (1989) and Yin (2015). Yin and Graham (1989, 1994) and Yin (2015) explained that these "time lines" can be interoperated as "equivalent time" lines. The word of "equivalent" here means that the creep strain rate at a certain stress-strain state, which is reached under any loading path, is equal to the creep strain rate at the same point, which is reached from a normal 1-D creep test loading path with the creep duration time $t$ from a reference time line. The time $t$ here is considered to be the "equivalent time" $t_{e}$ with $t=t_{e}$. Referring to Figure 4, we can run a normal 1-D creep test under a constant vertical stress from Point A to Point B (Path 1: A-to-B). It is well known that the creep strain rate decreases with time in this case. At Point B, there is still creep strain rate, say, $\dot{\varepsilon}_{z B(P a t h 1)}$. In another approach as shown in Figure 4, we can increase the vertical stress from Point A to Point C, and unload to Point B and then run creep test (Path 2: Point A-to-C-to-B). Under this loading path, we have creep strain rate $\dot{\varepsilon}_{z B(\text { Path } 2)}$. We have $\dot{\mathcal{E}}_{z B(\text { Path } 1)}=\dot{\varepsilon}_{z B(\text { Path } 2)}$. This means that the creep rate at Point B is dependent on the stress-strain (or void ratio) state, not on the loading path (Yin 2015).

For the creep compression in Figure 1, the authors suggest to use the following function to fit:

$$
e=e_{0}-C_{\alpha e} \log \frac{t_{0}+t_{e}}{t_{o}}
$$

where the parameter $C_{\alpha e}$ is newly defined in Eq.(7), called creep coefficient. It is noted that 
Eq.(7) has definition when time $t_{e}$ is zero. The $C_{\alpha e}$ in Eq.(7) is similar to the "secondary consolidation coefficient" " $C_{\alpha e} "$ as shown in Figure 1 and in Eq.(1). Why the authors use the same symbol $C_{\alpha e}$ as that in Eq.(1) is not to introduce a new symbol to make the new method difficult to be used by practicing engineers. In fact, the value of the newly defined $C_{\alpha e}$ is nearly equal to the value of the old " $C_{\alpha e}$ ".

In Eq.(7), $t_{0}$ is another independent creep parameter with unit of time. If $C_{c}$ and $C_{e}$ are determined from the compression with time 24 hours of duration, the authors propose $t_{o}=24$ hours=1day. If $C_{c}$ and $C_{e}$ are determined from the compression at the end of primary consolidation in lab with time $t_{E O P, l a b}$, then, the authors propose $t_{o}=t_{E O P, l a b}$. The choice of time $t_{o}$ and value of $C_{\alpha e}$ here does not make a significant difference to calculated creep strains.

The variable $t_{e}$ in Eq.(7) is the "equivalent time" as explained before. Eq.(7) is valid when time $t_{e}$ is zero, which is needed to consider creep occurring from the beginning of the loading. But in the old definition of " $C_{\alpha e} "$ in Figure 1, Eq.(1) is not valid when the time is or near to zero.

According to the "equivalent time" concept (Yin and Graham 1989, 1990), the total strain $\varepsilon_{z}$ at any stress-strain state in Figure 4 can be calculated by the following equation:

$$
\varepsilon_{z}=\varepsilon_{z p}+\frac{C_{c}}{V} \log \frac{\sigma_{z}^{\prime}}{\sigma_{z p}^{\prime}}+\frac{C_{\alpha e}}{V} \log \frac{t_{0}+t_{e}}{t_{o}}
$$

where $\varepsilon_{z p}+\frac{C_{c}}{V} \log \frac{\sigma_{z}^{\prime}}{\sigma_{z p}^{\prime}}$ is the strain on the normal consolidation line (NCL) under stress $\sigma_{z}^{\prime}$; and $\frac{C_{\alpha e}}{V} \log \frac{t_{0}+t_{e}}{t_{o}}$ is the creep strain occurring from the NCL under the same stress $\sigma_{z}^{\prime}$. The above equation is valid for any 1-D loading path. 


\section{Derivation of Specific Equations of the Simplified Method Based on Hypothesis B for Different Stress-Strain States}

With the equations (5), (6), (7) and (8) and the "equivalent time" concept, the authors derive the following specific equations for the calculation of the creep settlement $S_{\text {creep,f }}$ and the total consolidation settlement $S_{\text {totalB }}$ for different 1-D stress-strain states.

\section{Final stress-strain point in a normal consolidation state}

Referring to Figure 2, we assume the vertical stress is increased from the initial Point 1 to Point 4 which is on NCL. The total consolidation settlement $S_{\text {totalB }}$ is calculated by:

$$
\begin{aligned}
S_{\text {totalB }} & =S_{\text {"primary" }}+S_{\text {creep }} \\
& =U_{v} S_{f}+\left[\alpha S_{\text {creep }, f}+(1-\alpha) S_{\text {secondary" }}\right] \quad \text { for all } t \geq 1 \text { day } \quad\left(t \geq t_{E O P, \text { field }} \text { for } S_{\text {"secondary" }}\right)
\end{aligned}
$$

where

$$
S_{\text {creep }, f}=\frac{C_{\alpha e}}{1+e_{0}} \log \left(\frac{t_{o}+t_{e}}{t_{o}}\right) H
$$

where $H$ is the thickness of the soil layer. In this case, the "equivalent time" $t_{e}=t-t_{o}$, where $t$ is duration time of the current total vertical stress. Why $t_{e}=t-t_{o}$ is explained as follows:

Assume there is no porewater pressure coupling, this means $U_{v}=1$. From Eq.(9) and Eq.(6b), we have:

$$
\begin{aligned}
& S_{\text {totalB }}=S_{\text {"primary" }}+S_{\text {creep }} \\
& =\frac{C_{e}}{1+e_{o}} \log \frac{\sigma_{z p}^{\prime}}{\sigma_{z 1}^{\prime}} H+\frac{C_{c}}{1+e_{o}} \log \frac{\sigma_{z 4}^{\prime}}{\sigma_{z p}^{\prime}} H+S_{\text {creep }}
\end{aligned}
$$

It is noted that $S_{\text {creep }}=\left[\alpha \frac{C_{\alpha e}}{1+e_{0}} \log \left(\frac{t_{o}+t_{e}}{t_{o}}\right) H+(1-\alpha) \frac{C_{\alpha e}}{1+e_{0}} \log \left(\frac{t}{t_{E O P, \text { field }}}\right) H\right]$. Noting $t_{o}=1$ day (24 hours), and $t_{e}=t-t_{o}=t-1($ day $), t_{E O P, \text { field }}=1$ (day) since the compression index in Figure 2 is determined at 1 day. Therefore, at time $t=1$ (day), the creep settlement is 


$$
S_{\text {creep }}=\left[\alpha \frac{C_{\alpha e}}{1+e_{0}} \log \left(\frac{1}{1}\right) H+(1-\alpha) \frac{C_{\alpha e}}{1+e_{0}} \log \left(\frac{1}{1}\right) H\right]=0 .
$$

Eq.(10a) becomes:

$$
\begin{aligned}
& \left.S_{\text {total } B}=\frac{C_{e}}{1+e_{o}} \log \frac{\sigma_{z p}^{\prime}}{\sigma_{z 1}^{\prime}} H+\frac{C_{c}}{1+e_{o}} \log \frac{\sigma_{z 4}^{\prime}}{\sigma_{z p}^{\prime}} H \quad \text { (if } t=1 \text { day }\right) \\
& =\Delta \varepsilon_{\mathrm{z}, 1-4} H
\end{aligned}
$$

It is seen from Eq.(10b) that when time $t$ is 1 day, the stress-strain state point is at Point 4 on NCL. As explained before, the line NCL has duration of 1 day (or 24 hours) from a standard oedometer test.

It shall be pointed out that in Eq.(9), the settlement due to dissipation of excess porewater pressure represented by $U_{v}$ is de-coupled from the creep compression of the soil skeleton. This is why the present method is called a simplified one, compared to the fully coupled method in the section.

\section{Final stress-strain point in an over-consolidation state}

This section derives equations for calculation of the total consolidation settlement $S_{\text {totalB }}$ when the final loading stress-strain point is in an over-consolidation state after an additional vertical stress is applied. For example, Point 2, Point 5, and Point 6 in Figure 2 are all in an over-consolidation state. Firstly, we derive an equation for calculating the creep strain (or settlement) for a stress-strain point in an over-consolidation state. We use Point 6 as an example for this purpose.

According to the definition of "equivalent time" (Yin and Graham 1989, 1990), the creep strain rate at the present Point 2, no matter how to get this point in real situation, can be considered to reach Point 2 from Point $2^{\prime}$ on the extension of the normal consolidation line (NCL) by creep with an "equivalent time" value $t_{e 2}$. According Eq.(8), the strain at Point 2 $\varepsilon_{z 2}$ can be calculated as: 


$$
\varepsilon_{z 2}=\varepsilon_{z p}+\frac{C_{c}}{V} \log \frac{\sigma_{z 2}^{\prime}}{\sigma_{z p}^{\prime}}+\frac{C_{\alpha e}}{V} \log \frac{t_{0}+t_{e 2}}{t_{o}}
$$

From the above, we have:

$$
\begin{aligned}
& \log \frac{t_{0}+t_{e 2}}{t_{o}}=\left(\varepsilon_{z 2}-\varepsilon_{z p}\right) \frac{V}{C_{\alpha e}}-\frac{C_{c}}{C_{\alpha e}} \log \frac{\sigma_{z 2}^{\prime}}{\sigma_{z p}^{\prime}} \\
& \therefore \frac{t_{0}+t_{e 2}}{t_{o}}=10^{\left[\left(\varepsilon_{z 2}-\varepsilon_{z p}\right) \frac{V}{C_{\alpha e}}+\log \left(\frac{\sigma_{z 2}^{\prime}}{\sigma_{z p}^{2}}\right)^{-\frac{C_{c}}{C_{\alpha e}}}\right]}=10^{\left[\left(\varepsilon_{z 2}-\varepsilon_{z p}\right) \frac{V}{C_{\alpha e}}\right]} \times\left(\frac{\sigma_{z 2}^{\prime}}{\sigma_{z p}^{\prime}}\right)^{-\frac{C_{c}}{C_{\alpha e}}}
\end{aligned}
$$

From which, we obtain:

$$
t_{e 2}=t_{o} \times 10^{\left(\varepsilon_{z 2}-\varepsilon_{z p}\right)} \frac{V}{C_{\alpha e}}\left(\frac{\sigma_{z 2}^{\prime}}{\sigma_{z p}^{\prime}}\right)^{-\frac{C_{c}}{C_{\alpha e}}}-t_{o}
$$

It is seen from Eq.(11b) that the equivalent time $t_{e 2}$ at Point 2 is uniquely related to the stress-strain point $\left(\sigma_{z 2}^{\prime}, \varepsilon_{z 2}\right)$.

If we assume unloading from Point 1 to Point 2, the corresponding consolidation settlement can be calculated as:

$$
\begin{aligned}
& S_{\text {totalB }}=S_{\text {"primary" }}+S_{\text {creep }}= \\
& =U_{v} S_{f}+\left[\alpha S_{\text {creep }, f}+(1-\alpha) S_{\text {secondary" }}\right] \quad \text { for all } t \geq 1 \text { day } \quad\left(t \geq t_{E O P, \text { field }} \text { for } S_{\text {"secondary" }}\right) \\
& =U_{v} S_{f}+\left[\alpha \frac{C_{\alpha e}}{1+e_{0}} \log \left(\frac{t_{o}+t_{e}}{t_{o}+t_{e 2}}\right) H+(1-\alpha) S_{\text {secondary" }}\right]
\end{aligned}
$$

in which $S_{f}$ can be calculated using Eq.(6a). $t_{e}$ in Eq.(12) is the total "equivalent time" value for creeping from Point 2' to Point 2 and further downward.

The final creep settlement in eq.(12) is:

$$
S_{\text {creep }, f}=\frac{C_{\alpha e}}{1+e_{0}} \log \left(\frac{t_{o}+t_{e}}{t_{o}+t_{e 2}}\right) H
$$

which can be written:

$$
\begin{aligned}
& S_{\text {creep }, f}=\left[\frac{C_{\alpha e}}{1+e_{0}} \log \left(\frac{t_{o}+t_{e}}{t_{o}}\right)-\frac{C_{\alpha e}}{1+e_{0}} \log \left(\frac{t_{o}+t_{e 2}}{t_{o}}\right)\right] H \\
& =\Delta \varepsilon_{\text {zcreep }} H
\end{aligned}
$$




$$
\Delta \varepsilon_{\text {zcreep }}=\frac{C_{\alpha e}}{1+e_{0}} \log \left(\frac{t_{o}+t_{e}}{t_{o}}\right)-\frac{C_{\alpha e}}{1+e_{0}} \log \left(\frac{t_{o}+t_{e 2}}{t_{o}}\right)
$$

Referring to Figure 2, it is seen that $\frac{C_{\alpha e}}{1+e_{0}} \log \left(\frac{t_{o}+t_{e 2}}{t_{o}}\right)$ is the strain from Point 2' to Point 2; while $\frac{C_{\alpha e}}{1+e_{0}} \log \left(\frac{t_{o}+t_{e}}{t_{o}}\right)$ is the strain from Point 2 ' to Point 2 and further downward. The increased strain for further creep done from Point 2 is $\Delta \varepsilon_{\text {zcreep }}$, which is what we want to use it to calculate creep settlement under loading at Point 2. It is noted that the relationship between $t_{e}$ and the creep duration time $t$ under the stress $\sigma_{z 2}^{\prime}$ is:

$$
t_{e}=t_{e 2}+t-t_{o}
$$

Substitute Eq.(15) into Eq.(13), we have

$$
S_{\text {creep }, f}=\frac{C_{\alpha e}}{1+e_{0}} \log \left(\frac{t+t_{e}}{t_{o}+t_{e 2}}\right) H
$$

Therefore, the final total consolidation settlement is:

$$
\begin{aligned}
& S_{\text {total } B}=S_{\text {"primary" }}+S_{\text {creep }}= \\
& =U_{v} S_{f}+\left[\alpha \frac{C_{\alpha e}}{1+e_{0}} \log \left(\frac{t+t_{e 2}}{t_{o}+t_{e 2}}\right) H+(1-\alpha) S_{\text {secondary" }}\right] \quad \text { for all } t \geq 1 \text { day } \quad\left(t \geq t_{E O P, \text { field }} \text { for } S_{\text {"secondary" }}\right)
\end{aligned}
$$

Why is $t_{e}$ calculated using Eq.(14). The explanation is similar to that in Eq.(10).

If we consider the unloading from Point 4 to Point 6 in Figure 2, using the same approach as for the loading from Point 1 to Point 2, we can derive the following equations:

$$
t_{e 6}=t_{o} \times 10^{\left(\varepsilon_{z 6}-\varepsilon_{z p}\right) \frac{V}{C_{\alpha e}}}\left(\frac{\sigma_{z 6}^{\prime}}{\sigma_{z p}^{\prime}}\right)^{-\frac{C_{c}}{C_{\alpha e}}}-t_{o}
$$

The total consolidation settlement for unloading from Point 4 to Point 6 is:

$$
\begin{aligned}
& S_{\text {totalB }}=S_{\text {"primary" }}+S_{\text {creep }}= \\
& U_{v} S_{f}+\left[\alpha \frac{C_{\alpha e}}{1+e_{0}} \log \left(\frac{t+t_{e 6}}{t_{o}+t_{e 6}}\right) H+(1-\alpha) S_{\text {secondary" }}\right] \quad \text { for all } t \geq 1 \text { day } \quad\left(t \geq t_{E O P, \text { field }} \text { for } S_{\text {"secondary" }}\right)
\end{aligned}
$$

The following sections present the application and verification of the above equations of 
the new simplified Hypothesis B method.

\section{Application and Verification of the Simplified Method for Consolidation Settlement Calculation of Three Hong Kong Marine Clay Layers with Different OCR Values}

Hong Kong Marine Clays (HKMCs) in the seabed of Hong Kong waters are problematic soils for construction of infrastructures and houses on reclamations on HKMCs in Hong Kong. For the existing two runways of Hong Kong International Airport (HKIA) on Lantau Island, all marine clays in the seabed under the runways were dredged, moved, and dumped at another seabed location. HKIA is planning to construct a third runway. For environment and political concerns, all marine deposits, including HKMC, cannot be removed and must be kept or improved in situ. In this case, the settlement, especially the post-construction settlement will be a bigger concern to safe operation of the third runway. In fact, the current construction of artificial islands on the seabed of Hong Kong as part of Hong Kong-Zhuhai-Macau Link project $(29.6 \mathrm{~km}$ in length) will also face the problem of possible large settlements in the future.

In this section, authors select three idealized layers of HKMC (Figure 5) to apply the new simplified method with constant values of soil parameters to calculate the consolidation settlement up to 50 years for two layers with $1 \mathrm{~m}$ and $4 \mathrm{~m}$ thickness and 100 years for an $8 \mathrm{~m}$ layer. At the same time, two finite element programs using elastic visco-plastic (EVP) models are also used to analyze the same layers and results are used to evaluate the accuracy of the simplified method.

Koutsoftas et al. (1987) reported findings from site investigation at an offshore field test site in Hong Kong related to construction of the existing two runways of HKIA. They found that, at this site, there were an "Upper Marine Clay" layer in the top of the seabed (thickness from $2 \mathrm{~m}$ to $8 \mathrm{~m}$ ), underlain by an "Upper Alluvium" layer (thickness from $3 \mathrm{~m}$ to $8 \mathrm{~m}$ ), 
followed by a "Lower Marine Clay" layer (thickness from $5 \mathrm{~m}$ to $10 \mathrm{~m}$ ) and a "Lower Alluvium" layer (thickness from $6 \mathrm{~m}$ to $8 \mathrm{~m}$ ) in the seabed. Handfelt et al. (1987) reported the monitoring data of a test fill at this site. Zhu et al. (2001) developed and used a finite element program with Yin and Graham's 1D EVP model (Yin and Graham 1989, 1994) to analyze the consolidation settlement and excess porewater dissipation of the soils underneath the test fill.

In this section, authors select the "Upper Marine Clay" layer (called HKMC here) for consolidation analysis with values of soil parameters from papers by Koutsoftas et al. (1987) and Zhu et al. (2001). In order to better interpolate the creep settlement, different OCR values $(\mathrm{OCR}=1,1.5,2$,$) are adopted in the calculation and simulation. Two Finite Element$ (FE) programs are used for fully coupled consolidation analysis of the HKMC layers: one is software Consol developed by Zhu and Yin (1999, 2000), and the other one is Plaxis software (2D 2015 version). In the analysis, the 1D EVP model (Yin and Graham 1989, 1994) implemented in software Consol and a soft soil creep model in Plaxis software (2D 2015 version) are adopted in the FE simulations. The 1-D EVP model was applied by Zhu and Yin (1999, 2000 and 2001) for consolidation analysis. The description of the soft soil creep model is referred to Vermeer and Neher (1999) and Plaxis user's manual (2015). This soft soil model has been widely used in consolidation simulations by Degago et al. (2011) and Nash and Brown (2012).

The three layers of HKMC for calculation and simulation are shown in Figure 5. In Figure 5, the top three FE models are used for Consol analysis and the bottom three FE models for Plaxis analysis. The bottom of all layers is considered impermeable and the top of all layers is free to drain. The initial OCR value in the FE simulation is input easily in a menu in Plaxis; while this OCR value is calculated by giving the pre-consolidation pressure with depth in Consol software (Zhu and Yin, 2001). Values of all parameters used in FE consolidation simulation are listed in Table 1. In all FE simulations, a vertical stress of $20 \mathrm{kPa}$ is assumed to 
be instantly applied on the top surface and kept constant for a period of 18250 days (50 years) for two layers of $2 \mathrm{~m}$ and $4 \mathrm{~m}$ thickness and 36500 days (100 years) for the $8 \mathrm{~m}$ layer. The material properties reflect HKMC but the thicknesses and boundary conditions do not.

\section{The approach used by the simplified method for consolidation settlement calculation of a 2} m thick layer

For the simplified method calculation, referring to Figure 2, the initial and final stress-strain states in this $2 \mathrm{~m}$ thick layer must be correctly determined. Assuming the initial strain is zero under the initial stress state, while the initial effective stress state and pre-consolidation stress are different at different depths and different OCR values. If the thickness of a soil layer is less than $1 \mathrm{~m}$, we can assume the initial effective stress and pre-consolidation stress to be constant with negligible error. But for a thick layer, it is necessary to consider such variations. The total layer thickness in this case is $2 \mathrm{~m}$. We divide this layer into four soil sub-layers with $0.5 \mathrm{~m}$ thickness for calculation of consolidation settlement in order to obtain sufficiently accurate result.

Firstly, the initial effective stress state is determined from the saturated unit weight of the HKMC at the mid-depth of each sub-layer, considering the water unit weight as $9.81 \mathrm{kN} / \mathrm{m}^{3}$. Based on the initial effective stress state, the pre-consolidation stress and final effective stress state at the center of each part can be calculated from Eq.(20):

$$
\begin{aligned}
& \sigma_{z 0, i}^{\prime}=\left(\gamma_{\text {clay }}-\gamma_{w}\right) z_{i} \\
& \sigma_{z f, i}^{\prime}=\sigma_{z 0, i}^{\prime}+\Delta \sigma_{z}^{\prime} \\
& \sigma_{z p, i}^{\prime}=O C R \times \sigma_{z 0, i}^{\prime}
\end{aligned}
$$

where $z_{i}$ is the mid-depth location of each sub-layer $i, \Delta \sigma_{z}^{\prime}$ is the stress increment, taken as $20 \mathrm{kPa}$ in this calculation, $\sigma_{z 0, i}^{\prime}, \sigma_{z f, i}^{\prime}$ and $\sigma_{z p, i}^{\prime}$ are the initial effective stress states, final effective stress states, and pre-consolidation stresses for different depths soil sub-layers, respectively. Referring to Figure 2, the initial effective stress state is schematically at Point 1 
for $\mathrm{OCR}=1.5$ or 2 ; while the initial effective stress state is at Point 3 for $\mathrm{OCR}=1$ (a normal consolidation case).

Secondly, In this case, after the stress increase of $20 \mathrm{kPa}$, final effective is always larger than pre-consolidation stress for each sub-layer, which indicates that the final stress-strain state is in a normal consolidation state, that is, at Point $4\left(\sigma_{z 4}^{\prime}, \varepsilon_{z 4}\right)$ as shown in Figure 2. As a result, Eq.(6b) is adopted to determine the "primary consolidation" final settlement $S_{f, i}$ for each sub-layer $i$ of 0.5 thick for $\mathrm{OCR}=1.5$ or 2 , and Eq. (6c) is used the case of OCR=1. By summing "primary consolidation" final settlements of all sub-layers, the average values of coefficient of volume compressibility, $m_{v}$, and the coefficient of consolidation, $c_{v}$, can be obtained from Eq.(21):

$$
\begin{aligned}
& S_{f}=\sum_{i=1}^{n} S_{f, i} \\
& m_{v}=\frac{1}{H} \frac{S_{f}}{\Delta \sigma_{z}^{\prime}} \\
& c_{v}=\frac{k_{v}}{m_{v} \gamma_{w}}
\end{aligned}
$$

where $H$ is the thickness of the whole soil layer. Average values of $S_{f}, m_{v}$ and $c_{v}$ for different OCR values of the whole soil layer are listed in Table 2. It is noted that coefficient of volume compressibility, $m_{v i}$, and the coefficient of consolidation, $c_{v i}$ are different for different sub-layers. Thirdly, the time factor, $T_{v}$, and the average degree of consolidation, $U_{v}$, can be calculated by substituting the value of $c_{v}$ into following equations:

$$
\begin{array}{ll}
U_{v}=\sqrt{\frac{4 T_{v}}{\pi}} & \text { for } U_{v} \leq 0.6 \\
U_{v}=1-10^{-\left(\frac{T_{v}+0.085}{0.933}\right)} & \text { for } U_{v}>0.6
\end{array}
$$

where $T_{v}=\frac{c_{v} t}{d^{2}}$ and $d$ is the length of the longest drainage path. When top of the soil layer is drainage and the bottom is impermeable, $d=H$, while both top and bottom of the soil 
layer are drainage, $d=H / 2$. In this case, $d=2 m$ is adopted for the boundary condition mentioned above. Lastly, the creep compression is calculated by adopting Eqs.(9a) and (9b) since the final effective stress-strain state is in a normal consolidation state for all three OCR values.

In order to compare all methods for the creep settlement calculations, Hypothesis A method is also used to calculate the curve of settlement and $\log ($ time $)$ in both "primary consolidation" and the "secondary consolidation" period using Eq.(1).

\section{The approach used by the simplified method for consolidation settlement calculation of a 4} m thick layer

All the procedures and steps used in the $2 \mathrm{~m}$ thick layer case are adopted for consolidation settlement calculation of a $4 \mathrm{~m}$ thick layer case here. The final effective stress-strain state in all sub-layers of the $4 \mathrm{~m}$ thick later is in a normal consolidation state for all three OCR values. Values of the final settlement of "primary consolidation" $S_{f}$, the average values of coefficient of volume compressibility, $m_{v}$, and coefficient of consolidation, $c_{v}$, of the whole layer are obtained and listed in Table 2.

The approach used by the simplified method for consolidation settlement calculation of an 8 m thick layer

Following the same procedures used in the $2 \mathrm{~m}$ layer case, the initial effective stress state, final effective stress state, and pre-consolidation stress for each sub-layer $(0.5 \mathrm{~m})$ of an $8 \mathrm{~m}$ thick layer are determined. It is found that all the final effective stress states are in the normal consolidation state for $\mathrm{OCR}=1$, which means all calculations are similar to $4 \mathrm{~m}$ thick layer. However, it is found that some sub-layers of the soil are still in an over-consolidation state for 
$\mathrm{OCR}=1.5$ or 2 after the stress increment of $20 \mathrm{kPa}$. As a result, the total consolidation settlement for the final stress-strain state in the over-consolidation state should be considered in this section.

Take $\mathrm{OCR}=2$ as an example, the final stress-strain state after the $20 \mathrm{kPa}$ is in the normal consolidation state for each part of the top $4 \mathrm{~m}$ while over-consolidation state for the bottom $4 \mathrm{~m}$, corresponding to Point $2\left(\sigma_{z 2}^{\prime}, \varepsilon_{z 2}\right)$ in Figure 2. The "primary consolidation" final settlement $S_{f, i}$ of each part is calculated from Eq.(6b) for each sub-layer of the soil in a normal consolidation (NC) state; Eq.(6a) for each sub-layer of the soil in an over-consolidation (OC) state. Values of $S_{f}, m_{v}$ and $c_{v}$, of the whole layer can be calculated from Eq. (21) and listed in Table 2. Then, values of $T_{v}$ and $U_{v}$ are calculated using Eqs. (22). In order to obtain the creep compression with Eq.(13a) for the final effective stress state in an over-consolidation (OC) state, the "equivalent time" $t_{e 2}$ should be correctly calculated for each sub-layer using Eq.(11b). All values of "equivalent time" $t_{e 2}$ are using Eq.(11b) and are listed in Table 3.

Comparison and discussion of results from the old and new simplified Hypothesis $B$ methods, Hypothesis A method, and FE simulations

Settlements calculated using the old simplified Hypothesis B method ( $S_{\text {totalB-old }}$ ) (Yin 2011), Hypothesis A method ( $\left.S_{\text {totalA }}\right)$, two Finite Element (FE) simulations (Consol and Plaxis), and the new simplified Hypothesis B method ( $\left.S_{\text {totalB-new }}\right)$ for all three soil layers ( $2 \mathrm{~m}$, $4 \mathrm{~m}$, and $8 \mathrm{~m}$ ) mentioned above are examined in this section. It is noted that for each soil layer, we consider three Over-Consolidation Ratios (OCR) of 1, 1.5, and 2. Figure 6 shows comparison of settlement-log(time) curves from the old simplified Hypothesis B method $(\alpha=1)$, Hypothesis A method $(\alpha=0)$, two FE models (Consol simulation and Plaxis 
simulation), and the new simplified Hypothesis B method $(\alpha=0.8)$ for $\mathrm{OCR}=1,1.5$ and 2, respectively. It is found that the Plaxis simulation results with the soft soil creep model are in good consistence and agreement with results from Consol analysis using the 1D EVP model (Yin and Graham 1989, 1994). The FE models are for fully coupled consolidation analysis of soils with creep and shall be credible as the rigorous Hypothesis B method.

Comparing with the FE results in Figure 6, Hypothesis A method $(\alpha=0)$ underestimates the total settlement; while the old simplified Hypothesis B method $(\alpha=1)$ (Yin 2011) over-estimates the total settlement. In overall, the settlement curves calculated using the new simplified Hypothesis B method $(\alpha=0.8)$ is much closer to curves computed using Plaxis (2015) and Consol (Zhu and Yin 1999, 2000 ) when compared to other two methods.

Based on the comparison of curves in Figure 6 for three OCR values, it is observed that the curves from the old simplified method $(\alpha=1)$ are always below the curves from Plaxis and Consol simulations. The reason for the over-estimation of the settlement is that the creep part in Eq.(9b) in the old simplified Hypothesis B method is directly calculated based on the final effective stress-strain state, ignoring the time needed to arrive at this final effective stress state during consolidation (see Figure 2). The old simplified Hypothesis B method may be valid for a very thin soil layer, say less than $0.1 \mathrm{~m}$; while thicker soil layers need more time to arrive at the final effective stress-strain state, especially when hydraulic conductivity is low. The soil layer thickness in Figure 6 is $2 \mathrm{~m}$ with bottom impermeable and the time $t_{E O P}$ at $98 \%$ of consolidation is 4840 days for OCR equal to 1 . This is why the old simplified Hypothesis B method over-predicts the creep compression. To overcome this limitation, the authors have tried different values of $\alpha$ in Eq.(5) or Eq.(9). It is found that the value of 0.8 for $\alpha$ results in calculated curves which are in the best overall agreement with curves from Plaxis and Consol, not only for the layer thickness of $2 \mathrm{~m}$, but also for $4 \mathrm{~m}$ and $8 \mathrm{~m}$ cases (see Figures 6,7 , and 8).

The authors have calculated relative errors of the old simplified Hypothesis B method, the 
new simplified Hypothesis B method, and Hypothesis A method for the final settlements at 50 years for $2 \mathrm{~m}$ and $4 \mathrm{~m}$ layers by comparing with the settlements from Plaxis simulation. For example, the relative error for the new simplified Hypothesis B method is defined as:

$$
\text { relative error }=\left|\left(S_{\text {totalB, }- \text { new }}-S_{F E, \text { Plaxis }}\right) / S_{\text {FE, Plaxis }}\right|
$$

where $S_{\text {totalB-new }}$ is the total settlement calculated using the new simplified Hypothesis B at 50 years for $2 \mathrm{~m}$ and $4 \mathrm{~m}$ thick layers (or 100 years for $8 \mathrm{~m}$ thick layer) of HKMC; $S_{F E, \text { Plaxis }}$ is the settlement from Plaxis at the same time for the same layer.

All values of the relative errors are listed in Table 4. It is found that the relative errors of Hypothesis A method are in the range of $6.52 \% \sim 17.86 \%$ with under-estimation of the settlements. The relative errors of the old simplified Hypothesis B method are in the range of $5.71 \% \sim 12.16 \%$ with overestimation of the settlements. The relative errors of the new simplified Hypothesis B method are generally in the range of $0.99 \% \sim 8.42 \%$ with settlements closer to those from the two FE simulations.

Figure 7 presents the comparisons of curves calculated using the old simplified Hypothesis B method, Hypothesis A method, two FE models, and the new simplified Hypothesis B method for a soil layer with $4 \mathrm{~m}$ thick. Again, Hypothesis A method underestimates the total settlement during the whole stage. The curves from the new simplified Hypothesis B method are much closer to the curves from two FE simulations. Values of the relative errors are also listed in Table 4.

Figure 8 shows the comparisons of calculated curves using the old simplified Hypothesis B method, Hypothesis A method, two FE models, and the new simplified Hypothesis B method for an $8 \mathrm{~m}$ thick soil layer. Again, the curves from the new simplified Hypothesis B method are much closer to the curves from two FE simulations compared with other two methods. Values of the relative error are also listed in Table 4.

This paper has been built on the idea of 'equivalent times' proposed originally in Yin and Graham $(1989,1994)$. It assumes that viscous behaviour is a fundamental property of clays. 
More recently, Kelln et al. (2008) have expressed very similar ideas in terms of strain rates.

\section{Verification of the New Simplified Hypothesis B Method by Comparing Calculated Values with Test Data and Results from a Fully Coupled Consolidation Analysis}

Berre and Iversen (1972) presented a laboratory physical modeling study on the consolidation behavior of a natural post-glacial marine clay from Drammen exhibiting creep. Yin and Graham (1996) applied the 1-D Elastic Visco-Plastic (1D EVP) model in Eq.(3) in the fully coupled consolidation analysis in Eq.(2) of all consolidation tests by Berre and Iversen (1972). The consolidation problem was solved using a finite difference (FD) method. The calculated results were compared with the measured data and were found in a good agreement (Yin and Graham 1996). In this section, we use the old simplified Hypothesis B method and the new simplified Hypothesis B method to calculate the curves of average strain $\left(\Delta S / H_{0}\right)$ versus $\log ($ time) with a comparison with the test data and curves from the fully coupled consolidation analysis computed by Yin and Graham (1996) using a finite difference method (denoted as FD EVP model). Here $\Delta S$ is the settlement increment under Increment 5 and $H_{0}$ is the initial thickness of the soil layers in Test 6 and Test H4 in the original paper. Basic parameters used in the simplified methods are listed in Table 5. Values of initial stress, initial strain, and time duration for two tests at Increment 5 are listed in Table 6.

Since the tests consisted of multi-staged loading with various time durations, the stress-strain state should be correctly determined before the simplified method is used. And it is important to determine the pre-consolidation pressure $\sigma_{z p}^{\prime}$. Since both Point $\left(\sigma_{z 0}^{\prime}, \varepsilon_{z 0}\right)$ and Point $3\left(\sigma_{z p}^{\prime}, \varepsilon_{z p}\right)$ are on the reference time line, as shown in Figure 2, we shall have:

$$
\varepsilon_{z p}=\varepsilon_{z 0}+\frac{C_{c}}{V} \log \left(\frac{\sigma_{z p}^{\prime}}{\sigma_{z 0}^{\prime}}\right)
$$

Referring to Figure 2, If we assume the known initial stress-strain state is Point $1\left(\sigma_{z 1}^{\prime}, \varepsilon_{z 1}\right)$ on 
the over-consolidation line, there should be a relationship with the pre-consolidation pressure, Point $3\left(\sigma_{z p}^{\prime}, \varepsilon_{z p}\right)$, as follows:

$$
\varepsilon_{z p}=\varepsilon_{z 1}+\frac{C_{e}}{V} \log \left(\frac{\sigma_{z p}^{\prime}}{\sigma_{z 1}^{\prime}}\right)
$$

Combining Eqs.(23) and (24):

$$
\begin{aligned}
& \log \sigma_{z p}^{\prime}=\left[\left(\varepsilon_{z 1}-\varepsilon_{z 0}\right)+\left(\frac{C_{c}}{V} \log \sigma_{z 0}^{\prime}-\frac{C_{e}}{V} \log \sigma_{z 1}^{\prime}\right)\right] \frac{V}{C_{c}-C_{e}} \\
& \sigma_{z p}^{\prime}=10^{\wedge}\left[\left[\left(\varepsilon_{z 1}-\varepsilon_{z 0}\right)+\left(\frac{C_{c}}{V} \log \sigma_{z 0}^{\prime}-\frac{C_{e}}{V} \log \sigma_{z 1}^{\prime}\right)\right] \frac{V}{C_{c}-C_{e}}\right]
\end{aligned}
$$

With Eq.(25), the pre-consolidation pressure $\sigma_{z p}^{\prime}$ can be calculated, values of $\sigma_{z p}^{\prime}$ are listed in Table 6. After the increment stress, the final effective stresses in two tests are corresponding to Point 4. The calculation steps are similar to those in the previous sections. Values of the corresponding incremental final strain for "primary consolidation", the average values of $m_{v}$, and $c_{v}$, of the whole layer are also determined and listed in Table 6. Figure 9 shows a comparison of curves from tests, an FD EVP model, the old simplified Hypothesis B method, Hypothesis A method, the new simplified Hypothesis B method for Test 6 and Test H4 at Increment 5 .

Similar to those comparisons with curves from two FE simulations in Figures 6, 7, and 8, it is found that Hypothesis A method largely underestimates the average strain $\left(\Delta S / H_{0}\right)$, for Test 6 and Test H4. And curves from the old simplified Hypothesis B method agree well with the measured data for Test 6; while is quite below the test data for H4. It is noted that the soil specimen of Test H4 had thickness of $0.45 \mathrm{~m}$; while the specimen thickness of Test 6 was only $0.0757 \mathrm{~m}$.

When the correction factor $\alpha$ of 0.8 is applied, as shown in Figure 9, the curves from the new simplified Hypothesis B method are much closer to the test data. Values of the relative errors are listed in Table 7. The relative error here is defined as the absolute difference 
between the calculated value and the measured data at the end of the test over the measured data. Again, the relative errors of the new simplified Hypothesis B method are the lowest among all three simple methods.

With the verification of the new simplified Hypothesis B method by using test data from Berre and Iversen (1972), it is confirmed that the new simplified Hypothesis B method is more accurate than Hypothesis A method and the old simplified Hypothesis B method, and can be applied in reality to predict the one dimensional consolidation settlement of a single layer of soil with creep with good accuracy.

\section{Conclusions}

Based on the "equivalent time" concept, a new simplified Hypothesis B method has been proposed to calculate the consolidation settlement of a single layer of a clayey soil with creep for different stress-strain states. In order to verify the accuracy of the new simplified Hypothesis B method, the values from two fully coupled Finite Element (FE) consolidation analysis programs and previous laboratory measured data have been compared with curves obtained using the old simplified Hypothesis B method, the new simplified Hypothesis B method, and Hypothesis A method. Based on the results and discussion in the previous sections, main conclusions are drawn as follows:

(a) The proposed new simplified Hypothesis B method is a suitable simple method by spread-sheet calculation of the 1-D consolidation settlement of a single layer of a clayey soil with creep.

(b) For cases of three layers of Hong Kong Marine Clay (HKMC) with OCR of 1, 1.5, and 2, it is found that Hypothesis A method generally underestimates the consolidation settlement compared to the FE simulations. The relative errors for the three HMKC layers are in the range of $6.52 \% \sim 46.17 \%$, which is too large to be acceptable for any design.

(c) The old simplified Hypothesis B method (Yin 2011) overestimates the final consolidation 
settlement with errors in the range of $5.26 \% \sim 12.16 \%$ for all the cases of the three HKMC layers. The reason of the overestimation is that the creep part is calculated based on the final effective stress-strain state, ignoring the consolidation time (or the excess porewater pressure coupling) to arrive at this final stress state. To overcome this limitation, a correction factor $\alpha=0.8$ is used in the creep parts of the new simplified Hypothesis B method in Eq.(5). By comparison, it is found that results from the new simplified Hypothesis B method are much closer to curves from the FE simulations and data from tests. The relative errors of the new simplified Hypothesis B method are in the range of $0.37 \%$ to $8.42 \%$, the smallest among all three simplified methods.

(d) It is found that the curves from the new simplified Hypothesis B method are in good consistency and agreement with test data from Berre and Iversen (1972). This comparison verifies the accuracy and applicability of the new simplified Hypothesis B method.

Based on the comparison, discussion, and findings above, the authors recommend that the new simplified Hypothesis B method with $\alpha=0.8$ can be used for calculation of consolidation settlement of a single layer of a soil with creep for designs. The authors also recognise that more comparisons with fully coupled consolidation simulations and physical model tests are necessary to further examine the validation of this new simplified Hypothesis B method.

\section{Acknowledgement}

The work in this paper is supported by a research grant (project No. 51278442) from National Natural Science Foundation of China (NSFC), a general research fund (GRF) (project No. PolyU 152196/14E) from Research Grants Council (RGC) of Hong Kong Special Administrative Region Government of China, grants (4-BCAW, G-YM28, G-YN97, B-Q43L) from The Hong Kong Polytechnic University, China. 


\section{References}

Barden, L. 1965. Consolidation of Clay with non-linear Viscosity. Geotechnique 15, No. 4, 345-362.

Barden, L. 1969. Time-dependent deformation of normally consolidated clays and peats. J. Soil Mech, Fdn Div. Am. Soc. Civ. Engrs, 95, SM1, 1-31.

Berre, T., and Iversen, K. 1972. Oedometer tests with different specimen heights on a clay exhibiting large secondary compression. Geotechnique 22, No. 1, 53-70.

Bjerrum, L. 1967. Engineering geology of Norwegian normally consolidated marine clays as related to the settlements of buildings. Geotechnique, 17, No.2, 83-118.

British Standard 1377-5. 1990. Methods of Test for Soils for Civil Engineering Purposes (Part 5). British Standsrds Institution, London.

Craig, R.F. 2004. Soil Mechanics, $7^{\text {th }}$ Edition, Published 2004 by Spon Press in New York.

Degago, S.A., Grimstad, G., Jostad H.P., Nordal, S., and Olsson, M. 2011. Use and misuse of the isotache concept with respect to creep hypotheses A and B. Géotechnique, 61, 10: 897-908.

Garlanger, J.E. 1972. The consolidation of soils exhibiting creep under constant effective stress. Geotechnique 22, No. 1, 71-78.

Gibson, R.E., and Lo, K.-Y. 1961. A theory of consolidation for soils exhibiting secondary compression. Publication 41, p.1-16. Oslo: Norwegian Geotechnical Institute.

Graham, J., Crooks, J.H.A., and Bell, A.L. 1983. Time effects on the stress-strain behavior of natural soft clays. Geotechnique, 33, 165-180.

Handfelt, L.D., Koutsoftas, D.C., and Foott, R. 1987. Instrumentation for test fill in Hong Kong. Journal of Geotechnical Engineering, ASCE, 113(GT2): 127-146.

Hinchberger, S.D., and Rowe, R.K. 2005. Evaluation of the predictive ability of two elastic visco-plastic constitutive equations. Canadian Geotechnical Journal, 42: 1675-1694

Kelln C., Sharma J.S., Hughes D., and Graham, J. 2008. An improved elastic-viscoplastic soil 
model. Can. Geot. J.; Vol. 45(21), pp. 1356-1376.

Koutsoftas, D.C., Foott, R., and Handfelt, L.D. 1987. Geotechnical investigations offshore Hong Kong. Journal of Geotechnical Engineering, ASCE, 96(SM1): 145-175.

Leroueil, S., Kabbaj, M., Tavenas, F., and Bouchard, R. 1985. Stress-strain-time rate relation for the compressibility of sensitive natural clays. Geoetchnique, 35, No.2, 159-180.

Ladd, C.C., Foott, R., Ishihara, K., Schlosser, F., and Poulos, H.J. 1977. Stress-deformation and strength characteristics. Proc. $9^{\text {th }}$ Int. Conf. Soil Mech. Fdn Engrg, Tokyo, 4210494. Estimating settlements of structures supported on cohesive soils. Special summer program

Mesri, G., and Godlewski, P.M. 1977. Time- and stress-compressibility interrelationship. J. of Geotechnical Engineering, ASCE, Vol.103, GT5, 417-430.

Mesri, G., and Choi, Y.K. 1984. Time effect on the stress-strain behaviour of natural soft clays [Discussion]. Geotechnique 34, No. 3, 439-442.

Nash, D.F.T., and Ryde, S.J. 2000. Modelling the effects of surcharge to reduce long term settlement of reclamations over soft clays. In proceedings of Soft Soil Engineering Conference, Japan, 2000.

Nash, D.F.T., and Ryde, S.J. 2001. Modelling consolidation accelerated by vertical drains in soils subject to creep. Geotechnique 51(3), 257 273.

Nash, D., and Brown, M. 2013. Influence of Destructuration of Soft Clay on Time-Dependent Settlements: Comparison of Some Elastic Viscoplastic Models. International Journal of Geomechanics, A4014004.

Olson, R.E. 1998. Settlement of embankments on soft clays. J. of Geotech. and Envi. Eng., Vol.124, No.4, 278-288.

Terzaghi, K. 1943. Theoretical soil mechanics. New York: Wiley.

Vermeer, P.A., and Neher, H.P. 1999. A soft soil model that accounts for creep. In proceedings of "Beyond 2000 in Computational Geotechnics10 Years of Plaxis International, Balkema, 249-261. 
Yin, J.H. 2011. "From constitutive modeling to development of laboratory testing and optical fiber sensor monitoring technologies", Chinese J of Geotechnical Engineering, 33(1), 1 15. (14 "Huang Wen-Xi Lecture" in China).

Yin, J.H. 2015. Fundamental Issues on Constitutive Modelling of the Time-dependent Stress-Strain Behaviour of Geomaterials. International Journal of Geomechanics, 15(5), A4015002, 1 9.

Yin, J.-H., and Graham, J. 1989. Visco-elastic-plastic modeling of one-dimensional time-dependent behaviour of clays. Canadian Geotechnical Journal, 26, 199-209.

Yin, J.-H., and Graham, J. 1994. Equivalent times and one-dimensional elastic visco-plastic modeling of time-dependent stress-strain behavior of clays. Canadian Geotechnical Journal, $31,42-52$.

Yin, J.-H., and Graham, J. 1996. Elastic visco-plastic modelling of one-dimensional consolidation. Geotechnique, 46, No.3, 515-527.

Zhu, G.F., and Yin, J.-H. 1999. Finite element analysis of consolidation of layered clay soils using an elastic visco-plastic model. Int'l J. of Num. and Ana. Methods in Geomechanics, Vol.23, 355-374.

Zhu, G.F., and Yin, J.-H. 2000. Elastic visco-plastic finite element consolidation modeling of Berthierville test embankment. Int'l J. of Num. and Ana. Methods in Geomechanics, Vol.24, 491-508.

Zhu, G.F., Yin, J.H., and Graham, J. 2001. Consolidation modelling of soils under the Test Embankment at Chek Lap Kok International Airport in Hong Kong using a simplified finite element method", Canadian Geotechnical Journal, Vol.38, No.2, 349-363. 


\section{Figure Captions}

Figure 1. Curve of void ratio versus log (time) and "secondary" compression coefficient

Figure 2. Relationship of void ratio (or strain) and $\log$ (effective stress) with different consolidation states

Figure 3. Relationship of void ratio and $\log$ (effective stress) from compressions at $t_{E O P, l a b}$ and $t_{24}$.

Figure 4. Relationship of void ratio and vertical effective stress in log-scale, time limes, loading paths, and creep rate

Figure 5. Three layers (free drainage in the top and impermeable in the bottom) of HKMC for consolidation analyses with thickness of (a) $2 \mathrm{~m}$, (b) $4 \mathrm{~m}$, and (c) $8 \mathrm{~m}$ : the top three models used for Consol analysis and the bottom three models used for Plaxis analysis

Figure 6. Comparison of settlement-log(time) curves from the old simplified Hypothesis B method, Hypothesis A method, two FE models, and the new simplified Hypothesis B method for $2 \mathrm{~m}$ thick layer: (a) $\mathrm{OCR}=1$; (b) $\mathrm{OCR}=1.5$; and (c) $\mathrm{OCR}=2$

Figure 7. Comparison of settlement-log(time) curves from the old simplified Hypothesis B method, Hypothesis A method, two FE models, and the new simplified Hypothesis B method for $4 \mathrm{~m}$ thick layer: (a) $\mathrm{OCR}=1$; (b) $\mathrm{OCR}=1.5$; and (c) $\mathrm{OCR}=2$.

Figure 8. Comparison of settlement-log(time) curves from the old simplified Hypothesis B method, Hypothesis A method, two FE models, and the new simplified Hypothesis B method for $8 \mathrm{~m}$ thick layer: (a) $\mathrm{OCR}=1$; (b) $\mathrm{OCR}=1.5$; and (c) $\mathrm{OCR}=2$

Figure 9. Comparison settlement/thickness $\left(\Delta S / H_{0}\right)-\log ($ time $)$ curves from two tests, an FD EVP model, the old simplified Hypothesis B method, Hypothesis A method, and the new simplified Hypothesis B method for (a) Test 6 and (b) Test H4 at Increment 5 


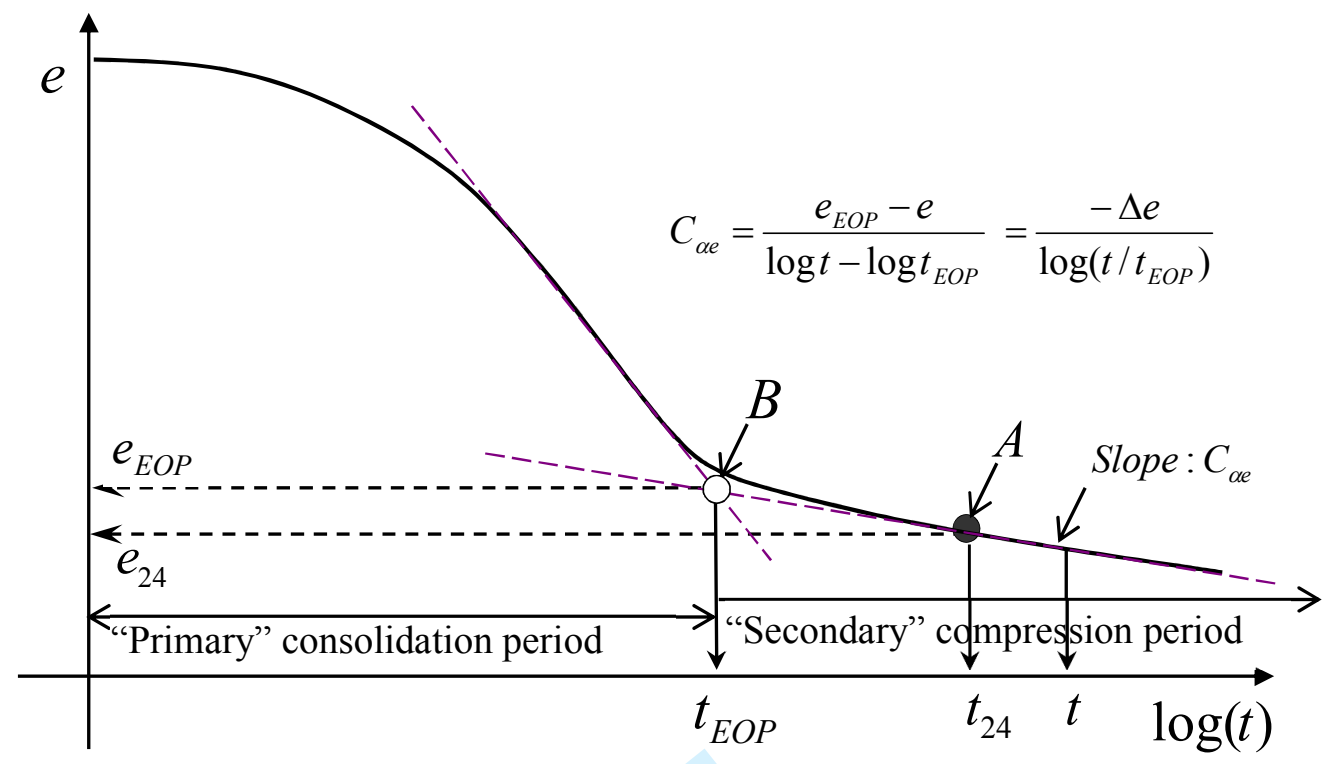

Figure 1. Curve of void ratio versus log (time) and "secondary" compression coefficient 


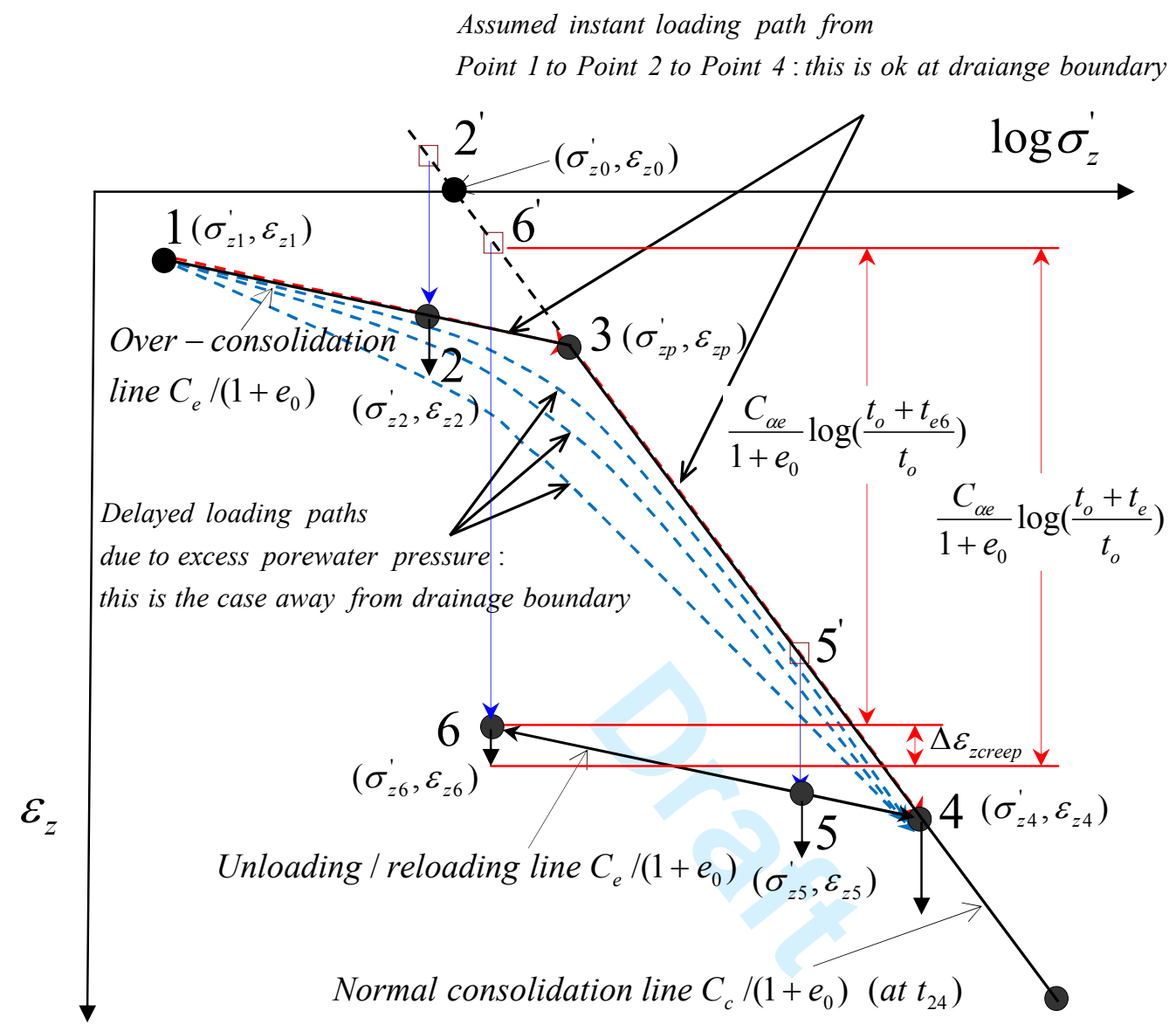

Figure 2. Relationship of void ratio (or strain) and $\log$ (effective stress) with different consolidation states 


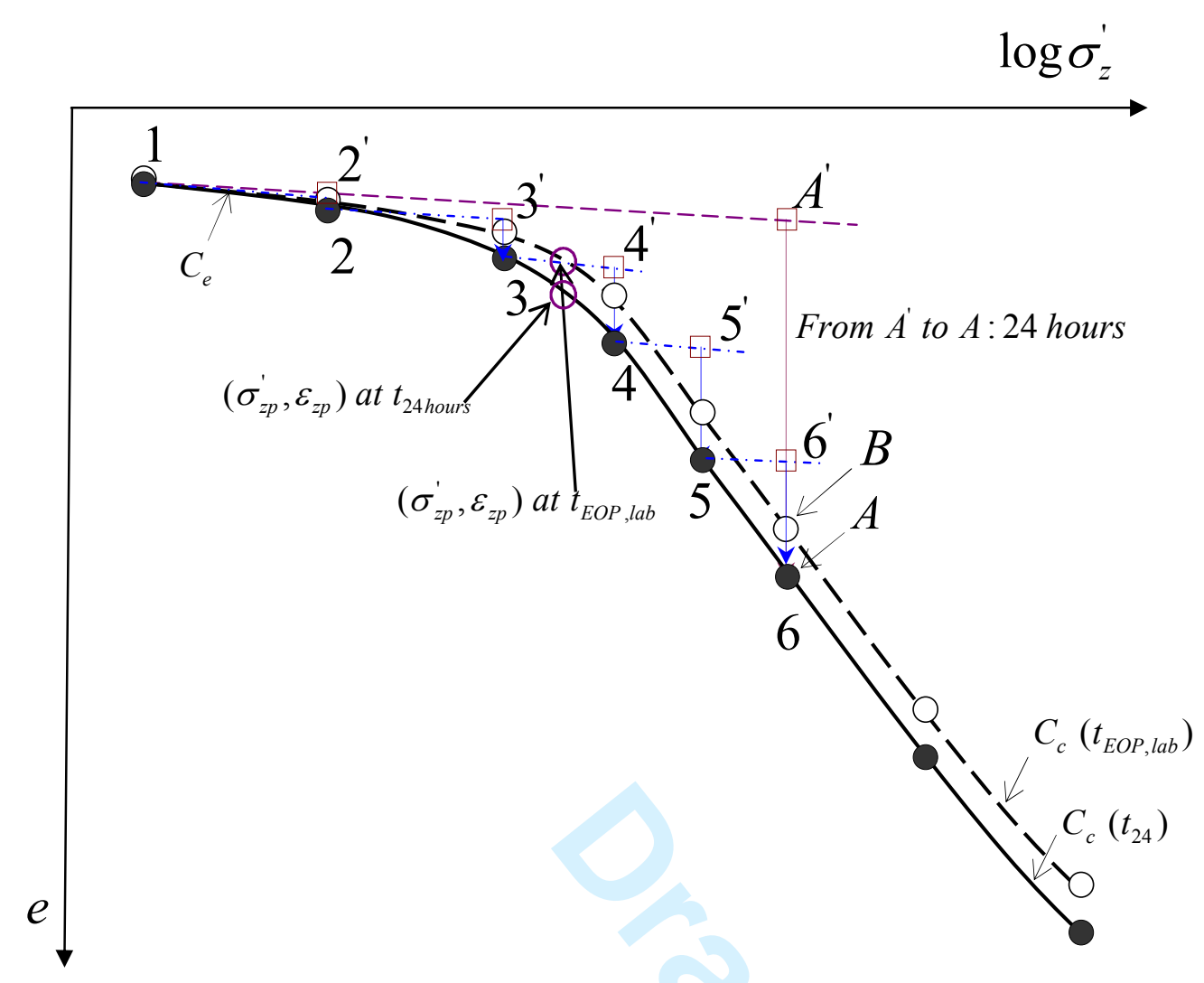

Figure 3. Relationship of void ratio and $\log$ (effective stress) from compressions at $t_{E O P, l a b}$ and $t_{24}$. 


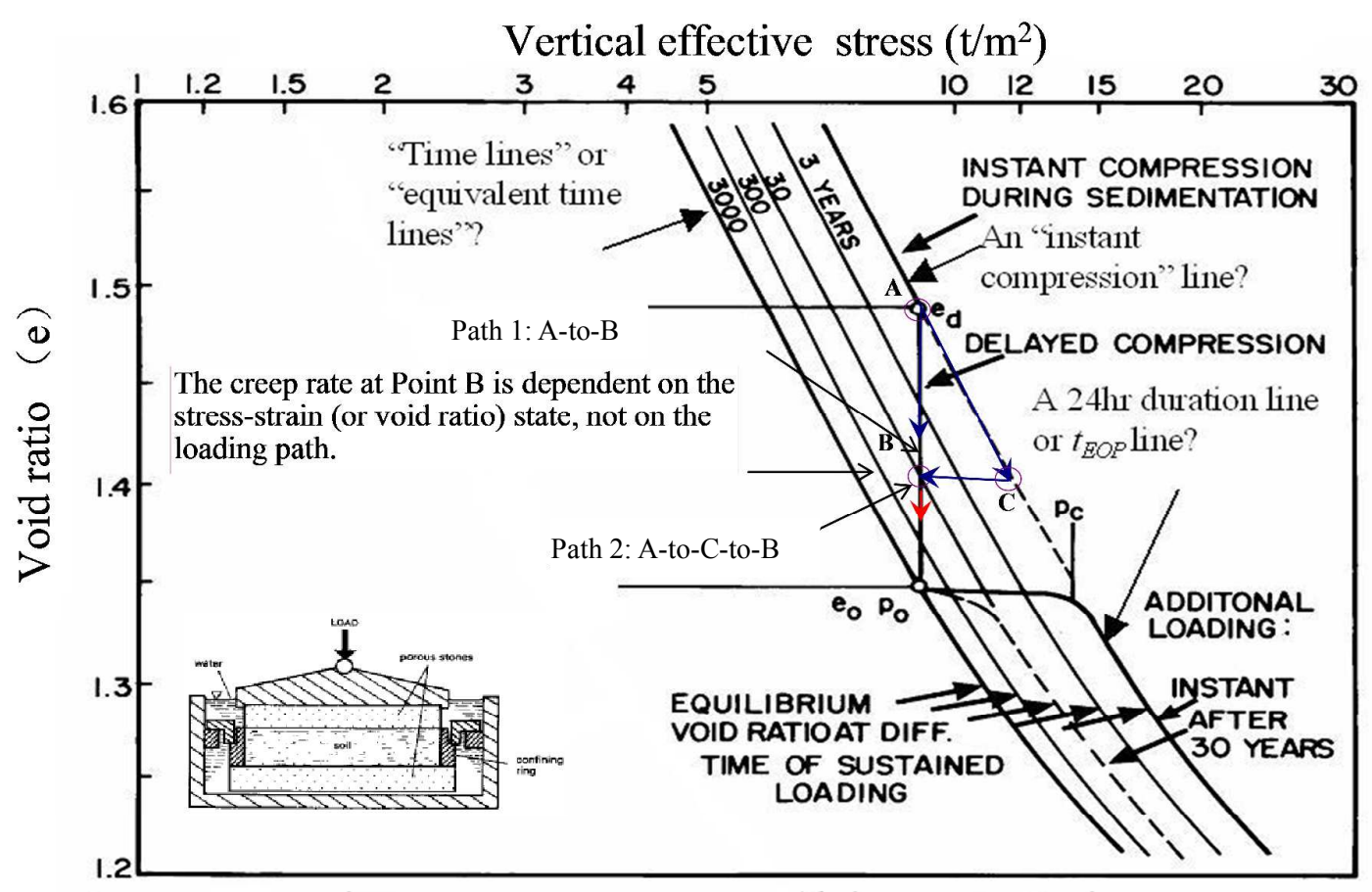

Figure 4. Relationship of void ratio and vertical effective stress in log-scale, time limes, loading paths, and creep rate 


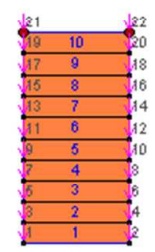

(a)

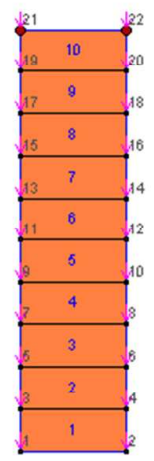

(b)

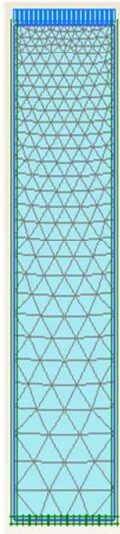

(b)

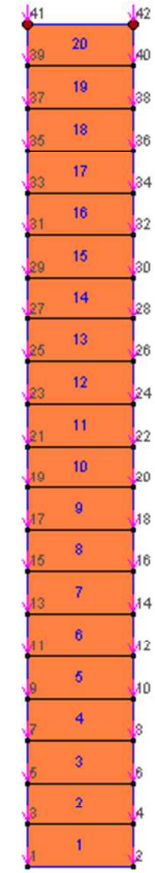

(c)

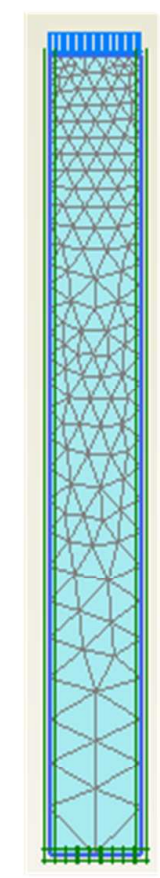

(c)

Figure 5. Three layers (free drainage in the top and impermeable in the bottom) of HKMC for consolidation analyses with thickness of (a) $2 \mathrm{~m}$, (b) $4 \mathrm{~m}$, and (c) $8 \mathrm{~m}$ : the top three models used for Consol analysis and the bottom three models used for Plaxis analysis 


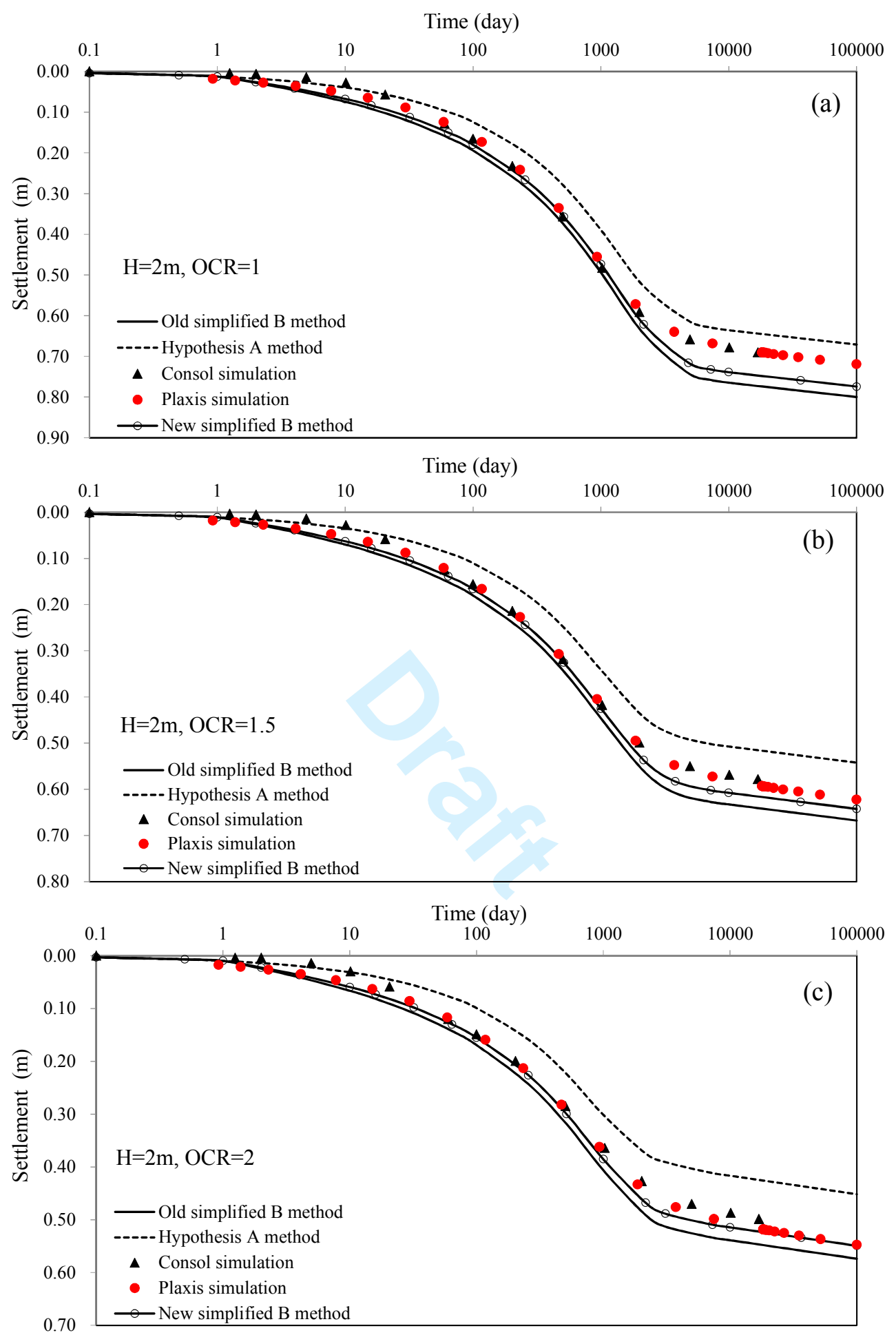

Figure 6. Comparison of settlement-log(time) curves from the old simplified Hypothesis B method, Hypothesis A method, two FE models, and the new simplified Hypothesis B method for $2 \mathrm{~m}$ thick layer: (a) $\mathrm{OCR}=1$; (b) $\mathrm{OCR}=1.5$; and (c) $\mathrm{OCR}=2$ 

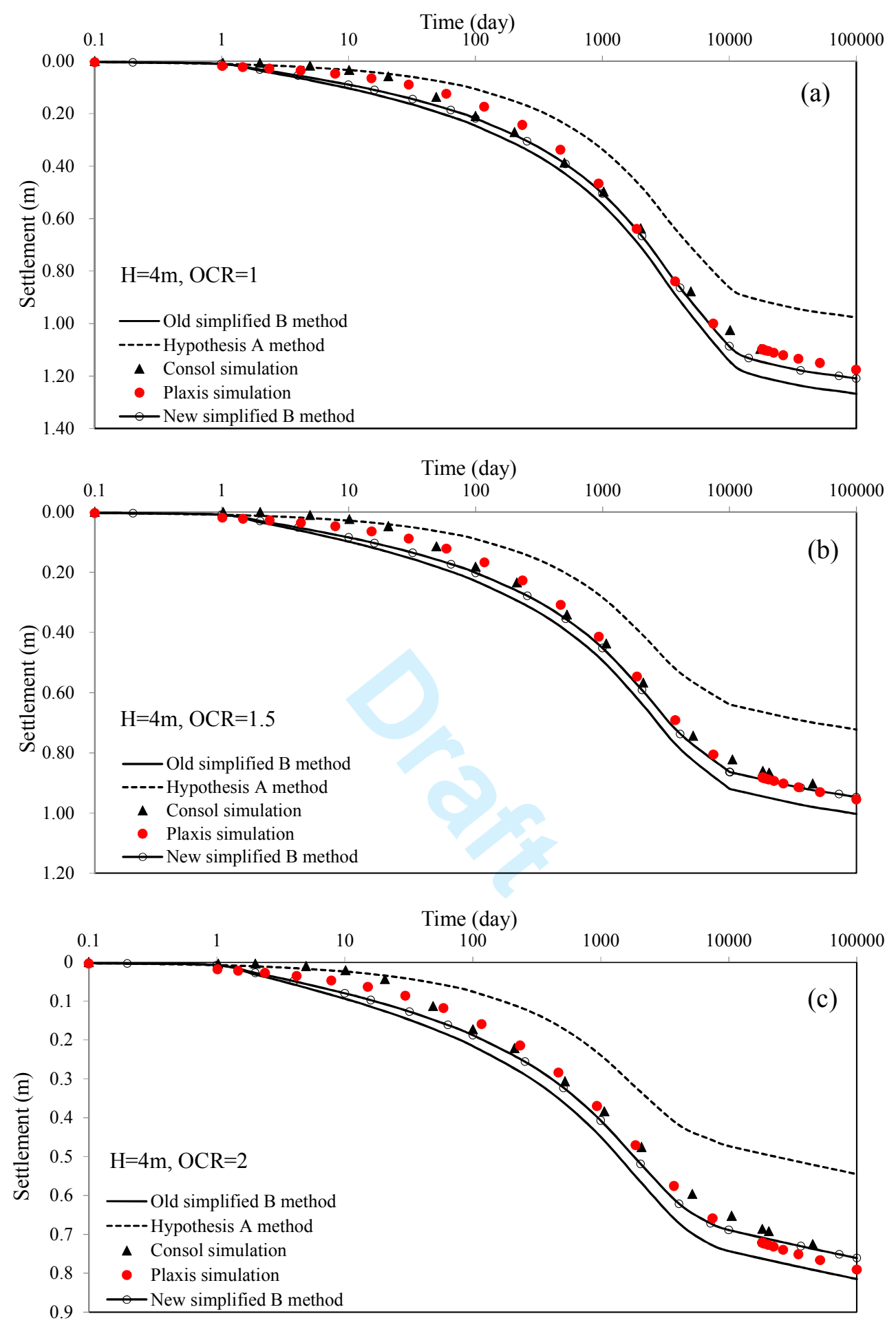

Figure 7. Comparison of settlement-log(time) curves from the old simplified Hypothesis B method, Hypothesis A method, two FE models, and the new simplified Hypothesis B method for $4 \mathrm{~m}$ thick layer: (a) $\mathrm{OCR}=1$; (b) $\mathrm{OCR}=1.5$; and (c) $\mathrm{OCR}=2$. 

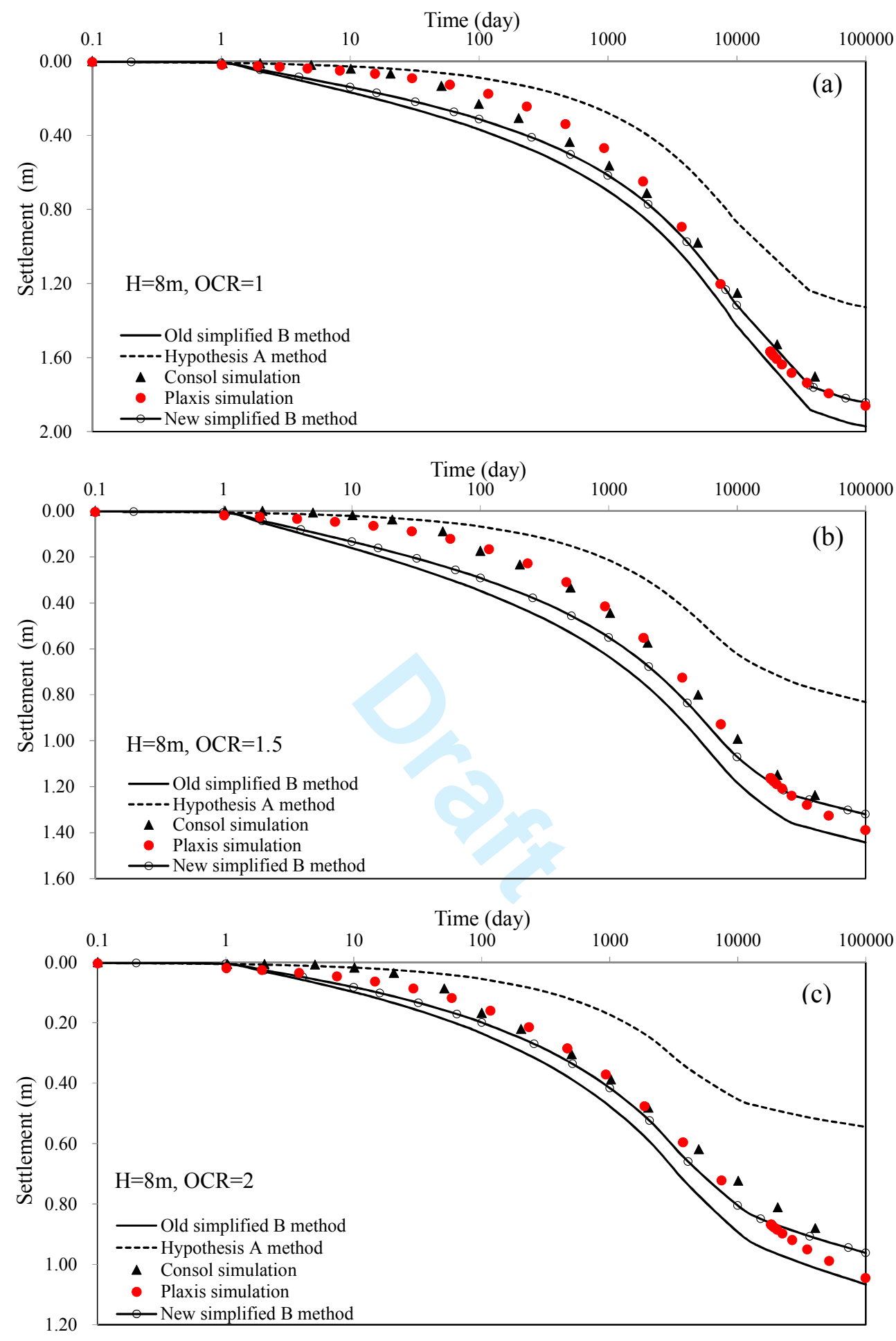

Figure 8. Comparison of settlement-log(time) curves from the old simplified Hypothesis B method, Hypothesis A method, two FE models, and the new simplified Hypothesis B method for $8 \mathrm{~m}$ thick layer: (a) $\mathrm{OCR}=1$; (b) $\mathrm{OCR}=1.5$; and (c) $\mathrm{OCR}=2$ 

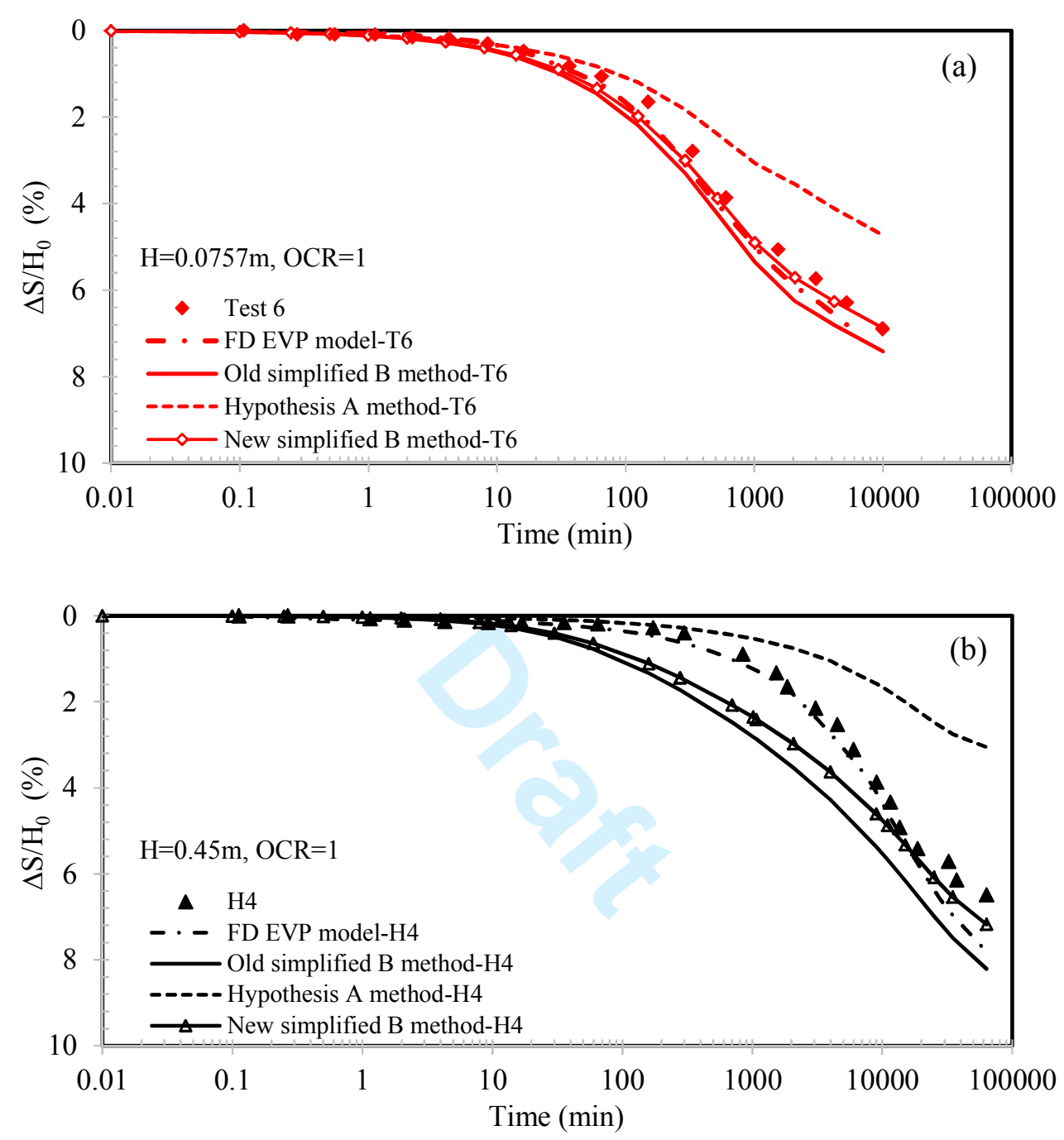

Figure 9. Comparison settlement/thickness $\left(\Delta S / H_{0}\right)-\log ($ time $)$ curves from two tests, an FD EVP model, the old simplified Hypothesis B method, Hypothesis A method, and the new simplified Hypothesis B method for (a) Test 6 and (b) Test H4 at Increment 5 
Table 1. Values of parameters for the upper marine clay of Hong Kong

(a) Values of basic property

\begin{tabular}{|c|c|c|c|}
\hline$V=1+e_{0}$ & $\begin{array}{c}\gamma_{\text {clay }} \\
\left(\mathrm{kN} / \mathrm{m}^{3}\right)\end{array}$ & OCR & $\begin{array}{c}w_{i} \\
(\%)\end{array}$ \\
\hline 3.65 & 15 & $1,1.5,2$ & 100 \\
\hline
\end{tabular}

(b) Values of parameters used in Consol software

\begin{tabular}{|c|c|c|c|c|c|}
\hline$\kappa / V$ & $\lambda / V$ & $\psi / V$ & $t_{0}$ & $k_{v}$ & $\sigma_{z 0}^{\prime} *$ \\
$(\mathrm{day})$ & $(\mathrm{m} /$ day $)$ & $(\mathrm{kPa})$ \\
\hline 0.01086 & 0.174 & 0.0076 & 1 & $1.90 \times 10^{-4}$ & 1 \\
\hline
\end{tabular}

*: $\sigma_{z 0}^{\prime}$ is the value of the effective vertical stress when the vertical strain of the reference time line is zero $\left(\varepsilon_{z 0}=0\right)$. Further details can be found in Zhu and Yin (2000).

(c) Values of parameters used in PLAXIS

\begin{tabular}{|c|c|c|c|c|c|c|c|}
\hline$\kappa^{*}$ & $\lambda^{*}$ & $\mu^{*}$ & $t_{0}$ & $k_{v}$ & OCR & $\begin{array}{c}c^{\prime} \\
(\mathrm{kPa}\end{array}$ & $\begin{array}{c}\phi^{\prime} \\
(\mathrm{deg})\end{array}$ \\
\hline 0.02172 & 0.174 & 0.0076 & 1 & $1.90 \times 10^{-4}$ & $1,1.5,2$ & 0.1 & 30 \\
\hline
\end{tabular}

(d) Values of parameters used in the new simplified Hypothesis B method

\begin{tabular}{|c|c|c|c|c|c|}
\hline$C_{e}$ & $C_{c}$ & $C_{\alpha e}$ & & $t_{0}$ & $k_{v}$ \\
{$\left[C_{e}=\kappa / \ln (10)\right]$} & {$\left[C_{c}=\lambda / \ln (10)\right]$} & {$\left[C_{\alpha e}=\psi / \ln (10)\right]$} & $V$ & $($ day $)$ & $(\mathrm{m} /$ day $)$ \\
\hline 0.0913 & 1.4624 & 0.0639 & 3.65 & 1 & $1.90 \times 10^{-4}$ \\
\hline
\end{tabular}


Table 2. Summary of main values used in the simplified Hypothesis B method

\begin{tabular}{|c|c|c|c|c|c|c|}
\hline \multirow{2}{*}{$\begin{array}{c}\text { Thickness } \\
(m)\end{array}$} & $\begin{array}{c}t \\
(\text { year })\end{array}$ & OCR & $\varepsilon_{z p}$ & $\begin{array}{c}s_{f} \\
(m)\end{array}$ & $\begin{array}{c}m_{v} \\
\left(\mathrm{kPa}^{-1}\right)\end{array}$ & $\begin{array}{c}c_{v} \\
\left(\mathrm{~m}^{2} / \text { day }\right)\end{array}$ \\
\hline \multirow{2}{*}{2} & \multirow{2}{*}{50} & 1 & 0 & 0.625 & 0.0156 & 0.00124 \\
\cline { 3 - 7 } & & 2 & 0.0075 & 0.399 & 0.0100 & 0.00194 \\
\cline { 3 - 7 } & \multirow{2}{*}{4} & 1 & 0 & 0.918 & 0.0115 & 0.00169 \\
\cline { 3 - 7 } & \multirow{2}{*}{50} & 1.5 & 0.0044 & 0.653 & 0.0082 & 0.00237 \\
\cline { 3 - 7 } & & 2 & 0.0075 & 0.465 & 0.0058 & 0.00333 \\
\hline \multirow{2}{*}{8} & \multirow{2}{*}{100} & 1.5 & 0.0044 & $0.742^{*}$ & 0.0046 & 0.00418 \\
\cline { 3 - 7 } & & 2 & 0.0075 & $0.487^{*}$ & 0.0030 & 0.00636 \\
\hline
\end{tabular}

*: means final stress states of some divided sub-layers are in the over-consolidation state. 
Table 3. Values of "equivalent time" $t_{e 2}$ for all sub-layers of $8 \mathrm{~m}$ layer with $\mathrm{OCR}=2$

\begin{tabular}{|c|c|c|c|c|c|c|c|}
\hline No. & $\begin{array}{c}\text { Depth at the } \\
\text { middle of each } \\
\text { sub-layer } \\
(m)\end{array}$ & $\begin{array}{c}\sigma_{z 0, i}^{\prime} \\
(k P a)\end{array}$ & $\begin{array}{c}\sigma_{z p, i}^{\prime} \\
(k P a)\end{array}$ & $\begin{array}{c}\sigma_{z f, i}^{\prime} \\
(k P a)\end{array}$ & $\varepsilon_{z p}$ & $\varepsilon_{z f, i}$ & $t_{e 2}$ \\
\hline $1 \sim 8$ & $0.25 \sim 3.75$ & $1.3 \sim 19.46$ & $2.6 \sim 38.93$ & $21.3 \sim 39.5$ & 0.0075 & - & 0 \\
\hline 9 & 4.25 & 22.06 & 44.12 & 42.06 & 0.0075 & 0.00701 & 1.79 \\
\hline 10 & 4.75 & 24.65 & 49.31 & 44.65 & 0.0075 & 0.00645 & 7.39 \\
\hline 11 & 5.25 & 27.25 & 54.50 & 47.25 & 0.0075 & 0.00598 & 20.40 \\
\hline 12 & 5.75 & 29.84 & 59.69 & 49.84 & 0.0075 & 0.00557 & 46.87 \\
\hline 13 & 6.25 & 32.44 & 64.88 & 52.44 & 0.0075 & 0.00522 & 95.43 \\
\hline 14 & 6.75 & 35.03 & 70.07 & 55.03 & 0.0075 & 0.00491 & 177.39 \\
\hline 15 & 7.25 & 37.63 & 75.26 & 57.62 & 0.0075 & 0.00463 & 306.61 \\
\hline 16 & 7.75 & 40.22 & 80.45 & 60.22 & 0.0075 & 0.00438 & 499.17 \\
\hline
\end{tabular}


Table 4. Settlements and relative error values for Hypothesis A method, the old and new simplified Hypothesis B methods for three HKMC layers

\begin{tabular}{|c|c|c|c|c|c|c|c|c|}
\hline $\begin{array}{l}\text { Case: layer } \\
\text { thickness } \\
\text { and year }\end{array}$ & OCR & $\begin{array}{c}S_{F E} \\
\text { Plaxis } \\
\text { FE result } \\
\text { (m) }\end{array}$ & $\begin{array}{c}S_{\text {totalA }} \\
(\mathrm{m})\end{array}$ & $\begin{array}{c}S_{\text {totalB-old }} \\
\text { (m) }\end{array}$ & $\begin{array}{c}S_{\text {totalB-new }} \\
\text { (m) }\end{array}$ & $\begin{array}{c}S_{\text {totalA }} \\
\text { error } \\
(\%)\end{array}$ & $\begin{array}{c}S_{\text {totalB-old }} \\
\text { error } \\
\quad(\%)\end{array}$ & $\begin{array}{l}S_{\text {totalB-new }} \\
\text { error } \\
\qquad(\%)\end{array}$ \\
\hline \multirow{3}{*}{$\begin{array}{c}2 \mathrm{~m} \\
50 \text { years }\end{array}$} & 1 & 0.690 & 0.645 & 0.774 & 0.748 & 6.52 & 12.16 & 8.42 \\
\hline & 1.5 & 0.593 & 0.516 & 0.642 & 0.616 & 12.91 & 8.22 & 4.00 \\
\hline & 2 & 0.518 & 0.426 & 0.548 & 0.523 & 17.86 & 5.71 & 0.99 \\
\hline \multirow{3}{*}{$\begin{array}{c}4 \mathrm{~m} \\
50 \text { years }\end{array}$} & 1 & 1.098 & 0.919 & 1.209 & 1.151 & 16.34 & 10.13 & 4.83 \\
\hline & 1.5 & 0.882 & 0.670 & 0.951 & 0.894 & 24.01 & 7.78 & 1.42 \\
\hline & 2 & 0.721 & 0.493 & 0.763 & 0.709 & 31.60 & 5.83 & 1.65 \\
\hline \multirow{3}{*}{$\begin{array}{c}8 \mathrm{~m} \\
100 \text { years }\end{array}$} & 1 & 1.742 & 1.238 & 1.877 & 1.748 & 28.95 & 7.70 & 0.37 \\
\hline & 1.5 & 1.286 & 0.768 & 1.379 & 1.257 & 40.24 & 7.24 & 2.26 \\
\hline & 2 & 0.955 & 0.514 & 1.005 & 0.907 & 46.17 & 5.26 & 5.02 \\
\hline
\end{tabular}


Table 5. Values of parameters used in the simplified Hypothesis B method based on data from Berre \& Iversen (1972)

\begin{tabular}{|c|c|c|c|c|c|c|}
\hline$C_{e}$ & $C_{c}$ & $C_{\alpha e}$ & & $t_{0}$ & $\sigma_{z 0}^{\prime}$ & $k_{v}$ \\
{$\left[C_{e}=\kappa / \ln (10)\right]$} & {$\left[C_{c}=\lambda / \ln (10)\right]$} & {$\left[C_{\alpha e}=\psi / \ln (10)\right]$} & & $(\min )$ & $(k P a)$ & $(\mathrm{m} / \mathrm{min})$ \\
\hline 0.0236 & 0.9313 & 0.0413 & 2.56 & 40 & 79.2 & $3.0 \times 10^{-6}$ \\
\hline
\end{tabular}

Table 6. Summary of main values calculated and used in the simplified Hypothesis B method at Increment 5 from Berre and Iversen (1972)

\begin{tabular}{|c|c|c|c|c|c|c|c|c|}
\hline Test No. & $\begin{array}{c}t \\
(\mathrm{~min})\end{array}$ & $\varepsilon_{z, 1}$ & $\sigma_{z, 1}^{\prime}$ & $\sigma_{z p}^{\prime}$ & $\sigma_{z, f}^{\prime}$ & $\Delta \varepsilon_{f}$ & $m_{v}$ & $c_{v}$ \\
$(\%)$ & $(k P a)$ & $(k P a)$ & $(k P a)$ & $\left(k^{-1}\right)$ & $\left(\times 10^{-6} \mathrm{~m}^{2} / \mathrm{min}\right)$ \\
\hline Test 6 & 5694 & 5.51 & 90.3 & 112.88 & 140.5 & 3.55 & 0.0744 & 4.11 \\
\hline Test H4 & 61450 & 5.25 & 89.2 & 111.05 & 134.7 & 3.14 & 0.0690 & 4.43 \\
\hline
\end{tabular}

Table 7. Relative error values for Hypothesis A method, the old simplified Hypothesis B method and the new simplified Hypothesis B method for three tests at Increment 5 from Berre and Iversen (1972)

\begin{tabular}{|c|c|c|c|c|c|c|c|}
\hline Test & $\begin{array}{c}\text { Test data } \\
(\Delta S / H) \\
\text { No. }\end{array}$ & $\begin{array}{c}S_{\text {totalA }} \\
(\Delta S / H) \\
(\%)\end{array}$ & $\begin{array}{c}S_{\text {totalB-old }}(\Delta S / H) \\
(\%)\end{array}$ & $\begin{array}{c}S_{\text {totalB-new }}(\Delta S / H) \\
(\%)\end{array}$ & $\begin{array}{c}S_{\text {totalA }} \\
\text { error } \\
(\%)\end{array}$ & $\begin{array}{c}S_{\text {totalB-old }} \\
\text { error } \\
(\%)\end{array}$ & $\begin{array}{c}S_{\text {totalB-new }} \\
\text { error } \\
(\%)\end{array}$ \\
\hline Test 6 & 6.905 & 4.64 & 7.415 & 6.86 & 32.79 & 7.38 & 0.65 \\
\hline Test H4 & 6.497 & 3.055 & 8.21 & 7.18 & 52.98 & 26.42 & 10.52 \\
\hline
\end{tabular}

